\title{
A play ground: Supporting interactions of children with autism through music therapy groups in a special education classroom
}

An exegesis presented in partial fulfillment of the requirements for the degree of

\author{
Masters of Music Therapy \\ New Zealand School of Music, Wellington \\ Aotearoa, New Zealand
}

Kathleen T. Sanders O'Connor

2013 
Children with autism face significant obstacles to social interaction and learning. This qualitative, exploratory study of student music therapy practice in a special education Unit, focused on supporting interactions of children with autism through music therapy groups integrated into the school programme. Clinical work took place over ten months, and the research employed secondary analysis of three data sources: clinical records, notes from supervision and staff meetings, and a reflective research journal.

Two complementary forms of music therapy groups, on the same day and with the same children, were developed: an established morning structured music therapy group, and at the end of the day, a free form music therapy group more like a typical playground. Findings suggest that the work of adults to engage the children, music play which attended to sensory sensitivities, promoting calm, giving new experiences and giving structured interaction opportunities contributed to an increase in the children's interactive behaviors in music therapy groups. When adults provided a free play community experience, the children showed an increase in initiating interactions and more expressive communications.

Eliciting emotional responsivity and giving patterned interactive experiences, through both improvisation and familiar music, seemed to build bridges with the children's communications and support motivation to interact.

\section{KEY WORDS:}

Music therapy

Autism

Special education

Sensory

Play

Emotional

Interaction

Community music therapy 
I would like to thank my family for all your support and love throughout my studies. To Ardis, Sophia, Evie and Jade O'Connor - you kept me going. To my parents, Freda and Des Sanders, and my sisters and brothers - Thank you!

Thank you to Sarah Hoskyns, my supervisor, and Daphne Rickson for your guidance and inspiration over the past five years. It has been a privilege to learn from you both. Thanks to Greg Gilbert at Learning Support, for your help towards the finish line! And to all the music therapy students in class - thanks for your companionship.

To the staff and students of the Unit - I am grateful for your trust and support. Thank you so much for all you have taught me, and for the music we made.

This research was conducted under the template for ethical approval for Master of Music Therapy student research granted by Massey University Human Ethics Committee: Southern A, Application- 11/41, 15th August 2011. 


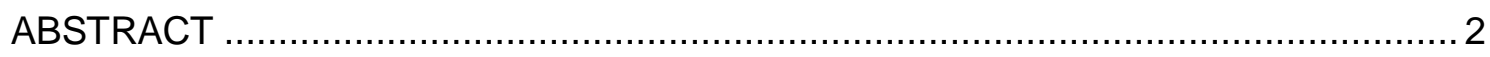

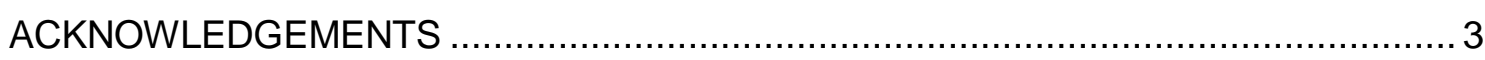

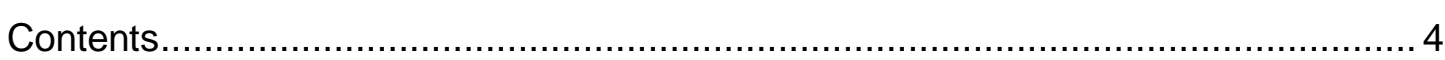

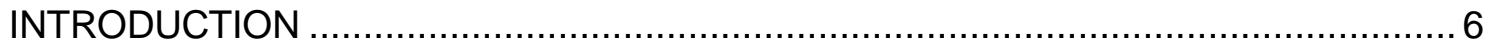

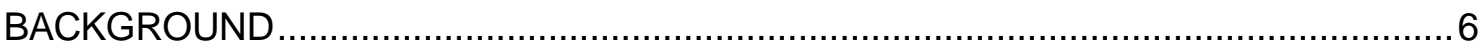

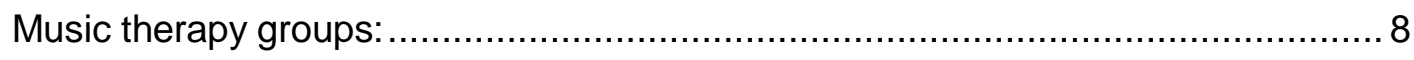

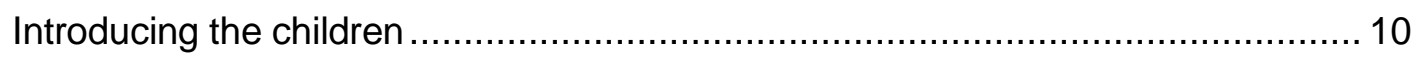

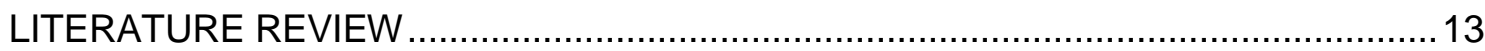

1. Play, child development and autism ............................................................. 13

2. Impact of sensory processing difficulties ................................................... 14

3. Music therapy and special education in Aotearoa New Zealand .......................... 15

4. Music therapy and autism ...................................................................... 15

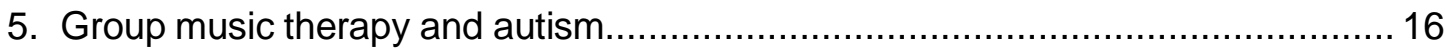

6. Community music therapy............................................................................. 17

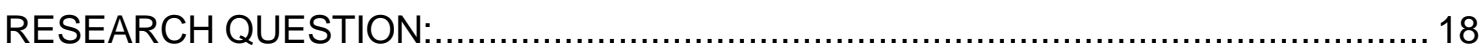

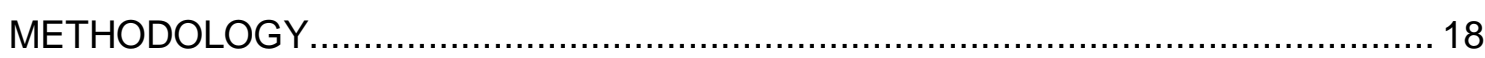

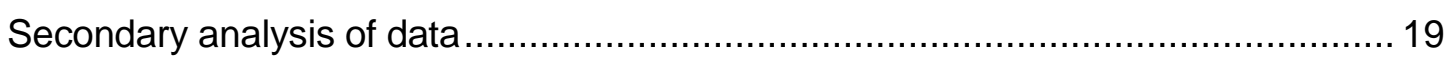

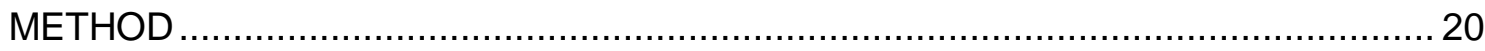

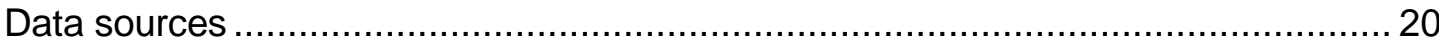

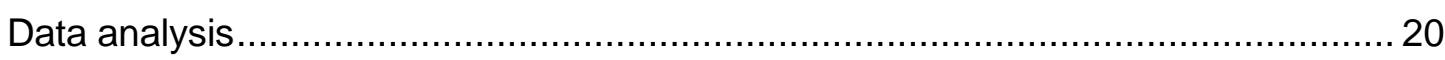

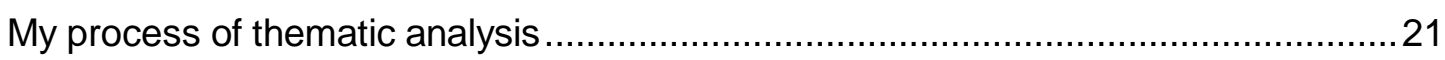

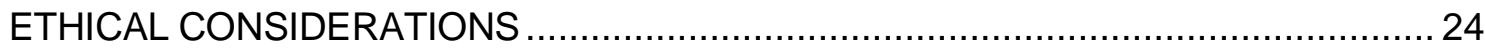

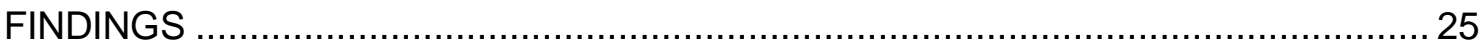

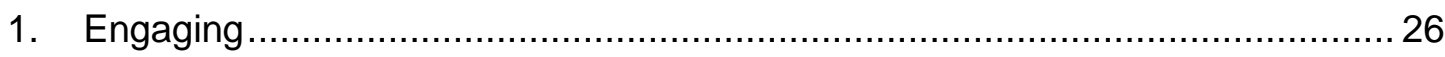

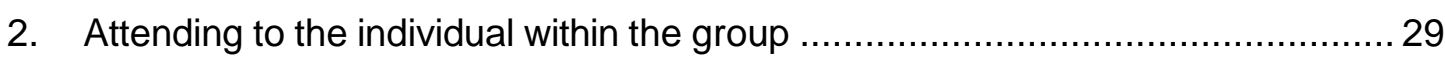

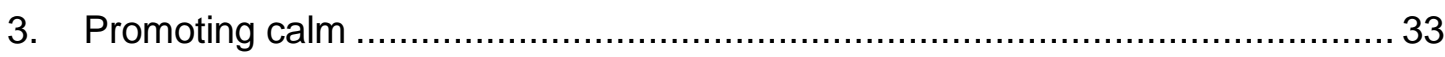

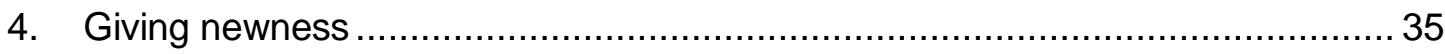

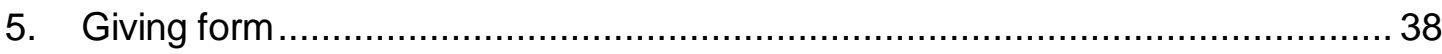

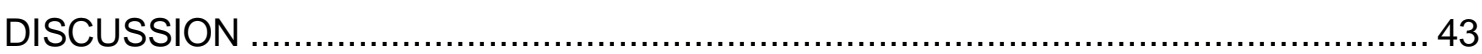

LIMITATIONS AND RELEVANCE

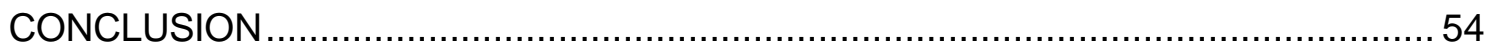

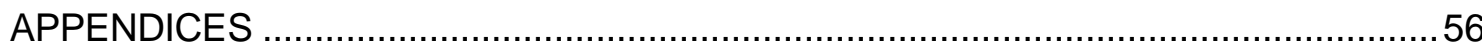

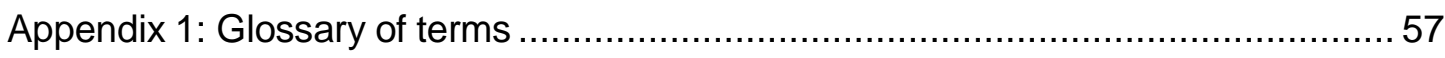

Appendix 2: Consent forms......................................................................... 58

Appendix 3: Sensory observations, emotional connections and music interactions. 64

Appendix 4: Examples of coding from data analysis ............................................ 72 
Appendix 5: Diagrams

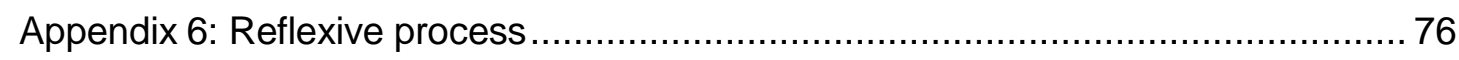

REFERENCES 
The purpose of this research is to explore and critically reflect on an aspect of my student music therapy clinical practice: supporting interactions of children with autism in two music therapy groups. Play is the domain of both childhood and music; the children's play, typically alone and repetitive made me wonder how music therapy might support their interactions and contribute to their education. Enhancing social interaction behaviours has relevance to increasing opportunities for the children to participate in society, as well as to the move towards the inclusive school environment mandated by the New Zealand government (Ministry of Education, 2012).

\section{BACKGROUND}

In this section I will provide descriptions of autism, the client group, the school programme, my initial observations of the children, my personal stance, my clinical approach, factors influencing my decision to work in group music therapy, the clinical work, a brief introduction to the children, group music therapy goals and conclude with comparisons of the two music therapy groups.

\section{Autism:}

Autism is described as a neuro-developmental condition, diagnosed by social, communicative and ritualistic behaviours. Additionally, intellectual disabilities, sensory and motor deficits are often evident, as well as the presentation of emotional difficulties and challenging behaviours. (Matson, Beighley and Turin, 2012).

\section{Client group:}

My supervised music therapy work was in a special Unit within a state primary school. The students, aged between five and ten years, were funded through the Ongoing Resource Scheme. This recognised these children had significant learning difficulties and would need substantial support throughout their schooling. The children were nonverbal; all were physically able, and needed adult supervision for their safety. Over the ten months of this study, three children left and one child joined the class whose number ranged from eight to ten children. There were usually twice as many boys as girls. All but one of the children had a diagnosis of classic autism, some with co-conditions (for example, Down Syndrome) and they were supported by almost one-to-one student-staff ratio. 


\section{The school programme:}

The Special Unit uses the Division TEACCH communication programme (Treatment and Education of Autistic and Communication Handicapped Children), developed specifically for children with autism. An individualized system sets out clear sequences of activities, which are developed from goals set out in the child's individual education plan. (Examples of goals were washing hands, matching sounds and pictures, taking one's plate to the bench after eating.) The TEACCH system, using pictures and structured use of learning tools helps these children engage more fully in their own learning, and to promote independent learning (Stewart, 2002).

\section{Initial observations of the children:}

Observing the children's play, I noticed how engaged and individual they were - sharing a physical space, and busy alone. The free play seemed to be characterised by repetitive, predictable behaviours for that child, both large motor activity and focused small motor activity, clear intention and sudden changes. Social interactions were brief and mostly in the form of requests to adults. I wondered about the impact of seeking and avoiding sensory stimulation on availability for interaction. I wondered about self regulation/self protection, and how group music interactions might assist children to overcome "resistiveness" (Nordoff, Robbins and Marcus, 2007).

\section{Personal stance}

I grew up in a large catholic family, in suburban Aotearoa New Zealand. My great grandparents came here from England and Ireland in the late $1800^{\text {ee }} \mathrm{s}$, as part of the wave of settlement which became the dominant culture over the indigenous Maori culture. Growing up, church, family and school were one, incorporating values of community and social justice. My undergraduate degree was in Theology, and I worked for several years in social work and in community development. With my husband, a Native American, and a teacher in a Waldorf Steiner school, we are raising our 3 teenagers within school communities informed by principals of anthroposophy. I have an interest in child development and I have worked assisting in kindergartens and group music with children. My family includes persons with Asperser's syndrome, and I have worked with adults with autism in supported residential work.

\section{Clinical approach}

My music therapy approach values the primacy of the therapeutic relationship as well as improvisation. I accept all behavior as communication and work in music for a person to become more of an agent in their own life. I think people can be resourced to find ways through obstacles and questions, which often leads to enhanced relationships, belonging and purpose. I respect the spirituality of each person; by this I mean their inner wellspring of inspiration and possibility. My music therapy work on the Unit 
aimed to be child-centred and playful, to enhance relationships and the children's capacities for learning.

My approach in this study has features in common with ,gentle empiricism ${ }^{\text {ee }}$ described as the legacy of Paul Nordoff and Clive Robbins music therapy research (Ansdell \& Pavlicevic, 2010). Although I am not Nordoff-Robbins trained, I value the emphasis on careful observation within a natural setting, and studied reflection on one's observations, as an active participant. The goal is to preserve the phenomena: what is happening in music therapy (for example, the child's interactions and resistance to interactions). I understand an aspect of this approach is to enjoy/celebrate the unique way a child presents and incorporate this in a dynamic interplay between therapist and child for meaningful music communication.

\section{MUSIC THERAPY GROUPS:}

My choice as a clinician to focus on music therapy groups was influenced by four factors:

a) My perception of the children's limited tolerance for the intensity of one-to-one interactions. Given the children's relatively short attention span, preference for brief interactions and avoidance of prolonged attention, I wondered about the potentials of group music therapy to contain, extend and somehow ,join together ${ }^{\text {ee }}$ possible interactions, and, perhaps to increase tolerance for being in groups, as a life skill.

b) The physical environment. The Unit had three classrooms, one large room at the entry, with two adjoining rooms. These were often in use, and the large room was like a play room, used at break times for free play. There were no other rooms in the school available for individual therapy. I found the physical environment more suitable for group work.

c) The structure of the school day. Mornings in the Unit were more structured, focused times of individual learning, and the daily morning music group was structured and well established. My goals for this group were joint attention, turn-taking, group awareness and a sense of belonging through listening, anticipation and participation in the group. Afternoons on the Unit, when the children were often tired, allowed for a variety of sensory play "when the children can be who they are" (P.Ross, Head teacher, personal communication, 20 March 2012) with less adult direction. The last hour of the day, was free play, where I hoped to provide some support and focus at a time that could be scattered. The open music session here provided opportunities for the children to initiate interaction/opt in to interaction, as well as to freely opt out/withdraw from interaction, as a way to support self regulation. I did not know if this fluid spontaneous music play might invite the children out of individual play and support interactions among students and with staff, or if the children would need more structured support to engage. The children showed almost exclusive preference for solitary activity yet seemed aware of what is happening in their environment. Would music in the classroom during free play facilitate interactions? 
d) My interest in community development. I wondered if group music therapy might underscore experiences of belonging as a class. I saw the benefit of supporting staff and I was interested in concepts from community music therapy of participation in and nourishing of the social context, in order to promote wellbeing of individuals.

\section{Clinical work:}

Along with individual music therapy sessions, I facilitated music therapy in an established, structured morning group and, in a new initiative, a free form music therapy group at the end of the same school day.

Individual music therapy: In the previous year, individual music therapy sessions with the children had been undertaken by a student music therapist on placement. During my clinical placement, each child in the study took part in at least one individual music therapy session per week; one-to-one music interactions also happened spontaneously, for example, in the playground, or when a child was distressed and needed withdrawal from their usual school programme. I was flexible about times for individual sessions, depending on what was happening for individual children on any given day and what worked for staff. I felt this approach was gave the children a natural experience of the spontaneous and unpredictable nature of social interaction; it fitted the children's generally brief attention span and gave opportunities for the children to use initiative to interact. In an empowerment model, it was a small way to enable the children to actively influence the timing of music therapy interaction, what it might begin with, and allowed for immediate positive feedback to their attempts to interact.

The Music Therapy Groups: The focus of this study is supporting the children's interactions through two complementary groups of music therapy which were:

A) An established daily music group at 10am. On the days I worked in the Unit, I led this group with support from staff, who led the group on other days.

B) A free form music group during free play time, between 2 and $3 \mathrm{pm}$ before the children went home. This latter session was to provide opportunity for the children to actively choose interaction, as well as to support the staff at a time of day when the children were often tired.

These two music groups occurred on the same day, with the same children. I worked either two or three days each week. Over the ten months of clinical practice, there were five blocks of work impacted by the four term school year, with two weeks of school holidays in between, and my month's leave from study for family reasons. The number of weeks in each block of work was as follows: five weeks, five weeks, two weeks, eleven weeks and another five weeks block.

I chose to focus on these two groups which already occurred in the school day, as places to support the children's interactions as well as to support the social environment of the Unit. I hoped these music sessions might be a context to address social engagement difficulties and thus to contribute to the children's education. 
Here I will present the four children in this study, followed by a descriptive summary of their interactions in the music groups.

Rewa was an eight year old Maori girl, physically strong, and well coordinated. Her physical movements were sudden and purposeful. She often sought vestibular movements, for example the swing or climbing equipment as well as tactile activities, for example rolling paper. Generally, she showed low sensory sensitivity. She often sought small spaces, and hid herself, and appeared watchful. During the school day she had times of intense distress, and appeared to have a high need to be in control; redirection was often very difficult for her. In music her "staying" behaviour was significant, because it was unusual for her. She enjoyed attention to her hands and feet, played variety of instruments, and her interactions were primarily vocal sound "dialogues". She usually participated vocally from across the room, occasionally coming in to the group for a "task". I used music to monitor her intensity of interaction, and she responded most to new music experiences, indirect attention, melodic and robust music.

Liam was an eight year old European boy, whose twin also with autism, was in mainstream education another school. Liam's self chosen activities were often a drop-and-catch ball play, twirling a string, and bouncing on the trampoline or swiss ball. He was active, strong and had very good eye/hand coordination. There were times he sometimes sought and enjoyed physical affection. When distressed he sought mouth stimulation. In music, Liam actively sought interaction with me, "listened" to music (stopped what he was doing, head on one side, a small smile) enjoyed rhythmic tapping on a woodblock, and could be influenced towards reciprocal music play with me when he was more available for interaction. Mostly he engaged in music easily, but seemed to need an adult's attention or an object/instrument as accompaniment to stay. He was able to be re-directed, anticipated simple patterns in music and at times could self calm by sitting quietly, listening and watching while sucking his thumb.

Susanna was a ten year old, European, girl; with a petite build and also with a diagnosis of Down syndrome. Often she was engaged in mouthing activity - she had her own strings of beads, made raspberry sounds, mouth clicks; sometimes she called out loudly and settled when responded to. Susanna often played in cushions with her whole body; she typically sought and maintained her own physical space. In music her interaction behaviours included being in physical proximity to me and others, staying within the group, tapping on me, touching the guitar, mouthing the strings, using the bells, xylophone, vocalising, face up, smiling, stopping individual play, making choice, making sounds in dialogue with me. I wondered if her "wa- oo" sound was part of our extended "hullo song" She indicated she had enough interaction by going back to her individual play or leaving the group.

\footnotetext{
${ }^{1}$ Names have been changed to protect the identity of the children.
} 
George was a gentle eight year old Somali boy, who was tall for his age. He actively sought movement, for example, rocking, walking, galloping and could run fast. He also actively sought tactile stimulation: he enjoyed attention to his hands and feet, splashing water and feeling beads and other textures. He liked to spin cords and often mouthed objects. In music he seemed to show auditory sensitivity; he was able to stay in the group when music was calm and predictable. He watched me closely, and seemed to enjoy waiting his turn for my attention or in a game. His interactive behaviours in music included instrument play, movement, playing the guitar with me, anticipating patterns, smiling and making a gentle "ee" sound.

\section{Music therapy goals:}

To provide music experiences which supported interactive behaviour of the children.

Music was selected in order to:

1. Elicit the children's responses

2. Develop children's awareness of each other, and of being in a group

3. Encourage vocalising

4. Support relational bonds children and staff

5. Increase children's abilities to stay engaged in a group, shown by their attention, listening and participation

\section{Examples of music experiences:}

Music to calm and support attention: guitar and singing, for example a composed song "It's OK"; lullabies; familiar children's songs, for example "Twinkle twinkle little star"; instrumentals and humming.

Music which was alerting of attention: "kia ora whanau" using finger clicking/clapping; use of woodblock; "La cucaracha" using a castanet and moving around the group, and the child who responded was given a turn; changing the tempo of music.

Music for participation: "Row, row, row your boat" and moving with a partner; music games using a shared object, for example, a slinky on elastic, hoola hoop or parachute; music which invited vocal responses, which were then incorporated into the song.

All music was improvisational in nature, the children's responses led to my adapting the material. My selection of music was dependant on immediate presenting needs as well as to promote group cohesion. 


\section{Comparison of the two complementary music therapy groups:}

\begin{tabular}{|c|c|}
\hline $\begin{array}{l}\text { MORNING STRUCTURED } \\
\text { MUSIC THERAPY GROUP }\end{array}$ & $\begin{array}{l}\text { AFTERNOON FREE FORM } \\
\text { MUSIC THERAPY GROUP }\end{array}$ \\
\hline $\begin{array}{l}\text { Compulsory participation for all children } \\
\text { except one child }\end{array}$ & Not compulsory \\
\hline $25-35$ minutes & $60-75$ minutes \\
\hline Small designated place, part of classroom & Large school playroom \\
\hline Close physical proximity expected & Close proximity to each other chosen \\
\hline $\begin{array}{l}\text { Beginning: children assembling for music } \\
\text { from other activities with staff. }\end{array}$ & $\begin{array}{l}\text { Beginning: some children finishing up } \\
\text { group sensory activity, some children } \\
\text { in free play }\end{array}$ \\
\hline $\begin{array}{l}\text { Music therapy student (MTS) led, staff } \\
\text { and children participating }\end{array}$ & $\begin{array}{l}\text { More shared leadership - interactions } \\
\text { initiated from adults } \\
\text { and children. More spontaneity and music } \\
\text { improvisations }\end{array}$ \\
\hline $\begin{array}{l}\text { Group attention to MTS as leader; staff } \\
\text { focus on group }\end{array}$ & $\begin{array}{l}\text { Many foci of attention, including MTS; } \\
\text { staff sometimes attending to other tasks or } \\
\text { another activity with a child }\end{array}$ \\
\hline Shorter individual interactions with MTS & Longer individual interactions with MTS \\
\hline Less conflict between children & $\begin{array}{l}\text { More conflict, caused by children seeking } \\
\text { MTS attention }\end{array}$ \\
\hline Intermittent attention to any one child & $\begin{array}{l}\text { Longer attention and accompaniment with } \\
\text { any one child }\end{array}$ \\
\hline More engagement as a group & $\begin{array}{l}\text { Less cohesive group, interactions and } \\
\text { alone play around the room }\end{array}$ \\
\hline More consistency of music choice & $\begin{array}{l}\text { More variety of music experiences, less } \\
\text { consistency }\end{array}$ \\
\hline
\end{tabular}

I have maintained an ongoing interest in developing my practice in music therapy with children with autism, and in particular, to find ways to enable these children to interact with others and their environment. Accepting these children with autism as they are, I acknowledge their significant, lifelong difficulties with social interaction. The power of music to draw a person into new and shared experiences, the potential of a music group to give scaffolding for interactions and self -expression, building tolerance through the vagaries of group dynamics, reinforcement of social belonging, along with the values of inclusion, and skills for life, are reasons to further explore how to support and enhance interactive skills within natural settings with this population

The focus of this study was to explore how I could support the children's interactive behaviours within the two different music therapy groups, in order to contribute to their education. 
I searched the Massey University library databases and bookshelves for writings to situate my study (on supporting interactions of children with autism) in the contexts of: education, autism, and group music therapy with children with autism. My need to find out more about interactions of children with autism led to further searching in the areas of play, and sensory processing; considering the social context for interactions, I also searched for community music therapy. I chose to begin with this review with sections relating to childhood interactions because the children are first of all children, before the ways I can think about them in academic categories, for example, autism, special education or therapeutic intervention. I organized the literature I found under the following headings:

1. Play, child development and autism

2. The impact of sensory processing difficulties

3. Music therapy and special education in Aotearoa, New Zealand

4. Music therapy and autism

5. Group music therapy and autism

6. Community music therapy

\section{PLAY, CHILD DEVELOPMENT AND AUTISM}

In this study about supporting children's interactions, it is relevant to consider play, defined as engagement with others and the environment (Corke, 2011). It has a central role in childhood, because play is both the means and the context of children's learning. Inherent in play are a myriad of opportunities for development of cognition, language, communication, social-emotional and sensory-motor domains (Mastrangelo, 2009). (Mastrangelo, 2009) Furthermore, children choose and are driven to play in ways that reinforce integration of their sensory systems, (Ayers, 1979) described below.

Play deficits are an indicator in the diagnosis of autism in children. Obstacles to play impact significantly on the learning opportunities of children; they often become further isolated from their peers by the increasing differences in their developmental stage and their play choices.

The presence of repetitive and restricted behaviours (RRBs) is a core feature of autism. Although RRBs are found in typically developing infants up to the age of 18 months (Leekham, Prior, \& Uljarevic, 2011) RRBs in children with autism, have been linked to sensory stimulation: they are thought to serve the purpose for the child of avoiding a challenging situation or to fulfill the need to increase stimulation (Gal, Dyck, \& Passmore, 2002) for regulation or from boredom. The presence of RRBs poses a major barrier to play and learning opportunities. (Leekham et al., 2011). 
Play is essential in childhood and predicates later development. Therefore, supported play is critical for children with autistic spectrum disorder and has been taught to these children (Barton \& Pavilanis, 2012; Ingersoll \& Schreibman, 2006).

\section{IMPACT OF SENSORY PROCESSING DIFFICULTIES}

Sensory processing refers to neurobiological functions of the body when it receives processes and integrates the many, complex constant sensations of daily life. There is a high incidence of reported difficulties of sensory processing in autism, (Lane, Young, Baker, \& Angley, 2010) and these have been associated with decreased abilities to engage socially.

Further description of sensory processing and how it impacts autism is offered by Berger (2002). Based on the seminal work of Ayers (1979), Berger (2002) links a neurobiological basis to behaviour which seeks or avoids sensory experiences. When there are severe inefficiencies in the working together of the seven sensory processing systems (vestibular, proprioceptive, tactile, olfactory, taste, auditory and visual) the person with autism often experiences the environment as a threat, and the fight/flight response is activated. Being in this state of high alert, the person with autism may then seek to order their world, through seeking or avoiding sensory input. Thus some "stereotyped" behaviour may well be a functional response to their physiology. She adds that connectedness and socialisation depend on the body feeling good (Berger, 2002).

The child with autism often presents with a mixed picture among the seven sensory processing systems. Hyper-reactive describes high sensitivity of one or more sensory system. Daily life can be experienced as overload and the person is easily overwhelmed. Hypo-reactive refers to under-responsivity, and thus the person's system needs more sensory input in order to support functioning. Further, there is sensory defensiveness, or fear responses to the environment. The fight-or-flight response is triggered by the unconscious brain's perception of threat and has called for a physical response. For example, peripheral vision and hearing are alerted. There also seems to be an impact on emotional and cognitive processing, where the person needs more time to respond and to understand. In the sensory environment of group music therapy, attention to a child's sensory profile and processing is described as being "of the utmost importance" (Goodman, 2007).

Further studies linking assistance given to supporting sensory differences and impact on participation have been recommended (Tomchek and Dunn, 2007). 


\section{MUSIC THERAPY AND SPECIAL EDUCATION IN AOTEAROA NEW ZEALAND}

A recent Ministry of Education Special Education publication "Kairaranga" identifies building positive relationships with students with on the autistic spectrum as key to effective education practice.(Bevan-Brown, Carroll-Lind, Kearney, Sperl, \& Sutherland, 2008). The authors note that these students often have difficulties in social communication, forming relationships and interacting with others, yet education programmes often do not prioritise building student/teacher and student/student relationships.

Currently, the Ministry of Education has a goal for including all children with wide ranging needs within main stream classrooms by 2014 (Ministry of Education, 2012). However, a review of Special Education Units found it likely these separate units will be part of the NZ education system for some time to come for students with high and very high education needs (McMenamin, 2011). Inclusion is clearly the goal, and therefore important to consider how to prepare students, currently in special education, towards participation in mainstream classrooms.

Music Therapy in Special Education in New Zealand has been valued (Twyford, 2009; Rickson, 2010) and has had a positive impact on children and educational teams Twyford (2009). Music therapy in this field is also evolving, variable (Rickson \& McFerren , 2007) and expanding into new ways of working (Twyford, 2009). The educational philosophy of inclusion, and changes in understanding about "disabilities" means the terms "special education" and "special needs" may be phased out. However, these terms are still commonly understood and used at present (Rickson, 2010). Rickson identifies inclusion as impacting on music therapy in school education settings. Describing the consultation model as a vital development for effectively delivering music therapy to students with special needs, she also points to a shift towards integrating music therapy into naturally occurring tasks and routines and away from "withdrawal for therapy" model (ibid, p17).

\section{MUSIC THERAPY AND AUTISM}

Autistic spectrum disorder is the client group with whom music therapy has had the highest reputation (Dmitriadis \& Smeijsters, 2011) drawing a person, isolated by their pathology, into musical interaction. "Successful" interactions, and "heard" selfexpression, influence experiences of self towards wellbeing. The communicative aspects of music therapy apply most clearly and directly to this population (Gold, Wigram, \& Elefant, 2010).

The music perception of children with autism is often intact and at level of, or above their peers (Simpson \& Keen, 2011). Therefore, promoting social interactions and communication through music has great potential with this population. Whipple (2004) in a meta-analysis of nine studies of any use of music, found music intervention was particularly effective with autism. The non-verbal elements of music communication (for example, rhythm, dynamics, melody) accommodate the child's abilities as well as minimising the linguistic component, often confusing for a person with autism (Dimitriadis \& Smeijsters, 2011; Gold et al., 2010). Further, the social-motivational 
aspects of music therapy, to invite and enable the child to engage emotionally, are highly relevant. Improvisational music therapy has the capacity to meet a child with autism where they are at; when the child realises the therapist's responses have to do with their communication and they are an agent in this event, the safety mechanism of needing to feel in control, is addressed (Kim, Wigram, \& Gold, 2009). Within the structure and flexibility of music interactions, the child can both lead and be challenged to be led, and there is the potential for rigid patterns to change (Wigram, 2004).

A Cochrane Review, using only randomised controlled trials or controlled clinical trials (Gold et al., 2010) reported positive effects of music therapy on communication skills of children with autism and music therapy was found to be superior to similar forms of therapy where music was not used. Although a small number of studies qualified, it is important to remember that evaluating positive changes, within a client, or within their lives often does not fit tidily into controlled research trials. Evaluating and describing the many interdependent variables of social interactions can be more suited to a qualitative approach. A narrative review of literature (Simpson \& Keen, 2011) found positive effects regarding music interventions with children with autism. These were in the areas of musical communication behaviours (Edgerton 1994) joint attention, more turn-taking, emotional synchronicity and initiating engagement (Kim et al 2009). They also reported significant evidence for the value of music therapy to promote social, emotional and motivational development in children with autism.

\section{GROUP MUSIC THERAPY AND AUTISM}

In the child with autism's unpredictable world, Tyler (2002) found group music therapy had potential to provide times of structure, support for interaction and self regulation. Nienhaus (2005), compared interactions in small group music therapy and daily life within an institution, and found that group music therapy offered supports for a more qualitative mode of interacting. She identified group size, physical proximity to each other and to staff, as well as the opportunity for spontaneity, all positively impacted on children's interactions. The most clear and significant contribution from music therapy was attention to detail in noticing and building upon the child's responses in music therapy. While acknowledging difficulties in identifying subtleties in communication, O'Connor used a Modified Behaviour Summarised Evaluation scale for group music therapy with children on the autistic spectrum, where all the children's abilities to interact improved (O'Connor, 2005).

Levels of social skills and emotional communication increased in a group music therapy pilot programme (which integrated Division TEACCH principles) with children with autism. The authors surmised that the music group provided a facilitating environment which enabled an increase in each child's autonomy, inter-subjectivity and emotional relating.(Stewart, 2002) Group music therapy gave a dynamic environment for working towards education goals of developing interaction skills (Nienhuis, 2005).

A Cochrane review (Gold et al., 2010) and narrative review (Simpson and Keen, 2011) of music therapy and autism identified significantly more studies of individual rather than group music therapy for children with autism. I found few group music therapy studies and these were undertaken in the past ten years. 
A narrative review highlights the importance of further studies to be undertaken in the children's natural environments (ibíd.). A randomised control trial, studying the effects of relational music therapy on communication of children with autism, (Gattino, dos santos Riesgo, Longo, Leite and Faccini, 2011) recommended the next study be undertaken in a school.

Considering suitability for inclusion in a music therapy group in a special education setting, children relating on a one-to-one level were included (Purvis and Samet, 1976, in Goodman, 2007). The relationship between interpersonal connectedness and musical sharing is a goal for a child in music therapy, as identified by Nordoff and Robbins, (1977). Their music therapy work included groups, although their writings do not include group case studies. Goodman is cautious about the suitability of music therapy groups for children with autism. Important considerations are the child's developmental level along with sensory profile and musicality of children. Drawing on twenty years of group music therapy practice with children with special needs, Goodman describes theory and practice of forming a cohesive group with children who have differing levels of functioning and tolerances for interactions. Referring to unpublished case notes, Goodman (2007) recommends more practice of music therapy infused into the natural setting of the school day, rather than activity based in a specific time and place.

\section{COMMUNITY MUSIC THERAPY}

A major contribution of Community Music Therapy has been attention to the social context of music therapy, influencing the development of the theory and practice of the music therapy profession. Described as "attuning to the flow of people, events and place as a musical event" (Pavlicevic, 2012) community music therapy weaves together the people and what they are doing in a particular place; it has potential to present a musical improvisation of what is happening and provide a stage for participation; participation which aims to enhance sense of self, social relationships and the group. Community music therapy moves away from a private setting into a communal place in order to enhance relational capacity of the members (Garred, 2006). Community music therapy seeks to enhance social relationships, and values inclusion, participation and belonging as key to health and wellbeing. This departs from a medical model of music therapy where experts provide treatment intervention to address deficiencies perceived in the patient or client. (Rickson, 2010). Inclusion moves the focus towards the social context and reducing any inherent barriers in order to enable access to participation Although community music therapy is beyond the scope of this study, its relevance here is because in the afternoon free form music therapy group I was hoping to support the children's interactions by nourishing relationships and experiences of belonging among students and staff in the Unit.

It would seem logical to engage in music therapy to support and enhance interactive behaviours within contexts where these behaviours can directly benefit the children with peers and teachers within every day settings. From a practical point of view, the current economic climate means music therapy in groups may be seen to be more cost effective for schools than individual music therapy. 


\section{How can a music therapy student support interactions of children with autism through two complementary music groups in a special education setting?}

\section{METHODOLOGY}

In this project I sought to discover how I supported interactions of the children with autism in two music therapy groups, through an analysis of clinical notes, my records of staff meetings, supervision and a reflective journal kept during ten months of student clinical work.

My research question, along with my approach in clinical work, lent itself to qualitative research, defined as:

a process wherein one human being genuinely attempts to understand something about another human being or about the conditions of being human by using approaches which take advantage of being human (Bruscia, 1995, p.426).

Drawing on Rudd's (1998, pp 108-109) considerations of qualitative music therapy research, qualitative research was deemed the optimal methodology because of its capacities to be "holistic" (encompassing therapeutic processes over time, and the interdependent influences of persons involved); b) "naturalistic" (the research was undertaken in a natural setting and on work already completed, thereby minimising the impact of research on what happened); c) "descriptive" (of interactions and experiences not able to be exactly replicated; they were often spontaneous and specific to the persons, time and place); and d) "reflexive" ( understanding and learning from my own clinical work, which included ongoing reading, I acknowledge my own values, interests and perceptions as the tools of interpretation.)

I was informed by "Gentle empiricism", a term describing the legacy of Paul Nordoff and Clive Robbins music therapy research (Ansdell \& Pavlicevic, 2010) Their tradition of "creative clinical music therapy research" (p. 134) involves careful observation of what happened in music therapy, as well as observation and reflection on oneself as active participant.

Similarly helpful to me as a student practitioner-researcher was Shoemark's (2009) explanation of the use of self-reflection linking a clinical supervision approach with a research approach. To Gold's $(2008$, p.2) pyramid of music therapy research (where the 
largest foundational level is theory, the middle section is practice, and the smallest top level is evidence) Shoemark adds a fourth aspect, the "Self". She explains that reflexive practice, in qualitative music therapy, allows on to review the impact of one's interpretations; and that depth of insight develops practice, research and writing. As I developed experience making the secondary analysis of data, I appreciated the benefit of using my own reactions and reflections as a research tool. This process is also noted widely in social science research (for example Lichtman's account in her 2013 user's guide to qualitative research (p 157-168).

In consultation with my supervisor, we considered secondary analysis of data an appropriate research strategy to explore my student practice because of the inherent ethical safeguards, the many opportunities to learn about the impact of my student practice and the fit with my clinical approach. The data set had been naturally generated as part of usual clinical work.

\section{SECONDARY ANALYSIS OF DATA}

This is a research strategy which analyses pre-existing data, for purposes different to those for which it was originally collected, in order to investigate new questions. (Heaton, 2004). Three modes of secondary analysis of data have been identified. In the first, independent researchers using data collected by another person or group; in the second, researchers work with a mix of independently and self-collected data. The research employed in this study uses the third mode, referred to as ,auto-data ${ }^{\text {ee }}$ where researchers re-use their own data (Hennink, Hutter and Bailey, 2011, p 15).

Secondary analysis of ,auto-datae is an appropriate method for music therapy research due to the existing data generation practices in the therapy process. For practitioners, nurses and music therapists for example, important and rich data are generated as part of clinical practice. Lobo (in Heaton, 2004) states this can contain much information about practitioner's actions, and the impact of their actions on clients.

Secondary analysis of data, using the ,auto-data ${ }^{e e}$ mode, had the following advantages: Firstly, clinical practice was delineated from the research; the research took place on clinical data, collected as part of usual practice and already completed. This meant clinical work took place as usual and there were no direct participants in the study. Secondly, this research strategy afforded the opportunity for me to carefully analyse my own work, to learn from practice by uncovering themes, what might have been missed, and assumptions, while in training and under supervision. Thirdly, it integrated practice and research, for example, by following an enquiry guided by the students ${ }^{\text {ee }}$ research question which arose from the work.

Secondary analysis of data has links with "clinical data mining" defined as "the practitioners "e use of available agency data for practice based research purposes" (Epstein, 2001 p.3). Epstein points out the great potentials in existing data, collected as part of usual practice, for research purposes. He states that benefits of this methodology include cost effectiveness, engagement of practitioners in research and their subsequent knowledge development and production. 
As stated, my research strategy was secondary analysis of data, where my clinical notes, compiled as part of usual clinical practice, were investigated through the lens of my research question. This created a distance or delineation between completed clinical work and research. There were no participants in the research. My specific method of data analysis was thematic analysis, and this process is described below after the three data sources.

\section{DATA SOURCES}

The three data sources consisted of:

a) Clinical notes from both group music therapy sessions, along with individual profiles I built up of my observations of sensory preferences and sensitivities, emotional responses and music interactions (I shared these with the Head teacher and received feedback).

b) Notes from supervision and staff meetings, my student assessments, class support, peer supervision and two check points where I self assessed

c) Reflective research journal - here I documented my interpretations, feelings, questions and struggles, in an effort to come to new understandings. For example, most journal entries I tried to encapsulate in a sentence what was the experience of a session: what was significant (for the children and/or for me) and why (Verney and Ansdell, 2010). My journal also included my cathartic emotional expressions from the school day as well as new learning about the work from reading. The journal was tool for self-awareness; how I was influencing and being influenced by the clinical work.

Clinical notes were written in brief after each group, and often added to at the end of each day of placement or on my weekend. In the main, my notes from the two music groups and individual case notes were recorded on my lap-top computer, and supervision, staff meetings, and reflective journal notes were generally written by hand and kept in folders.

\section{DATA ANALYSIS}

I employed thematic analysis, commonly used in qualitative research to identify, analyse and report patterns and themes within the data. The analysis was both inductive, as codes were identified from within the data, and deductive: guided by my research question and interpretation. Thematic analysis can give a rich overall description of data, and has been found to be useful when the indirect participants (i.e. the children) cannot give their views (Braun and Clarke 2006). 
Reflexivity has been described as an underlying principle of qualitative research and the premise upon which to make use of qualitative research evaluation concepts proposed by Stige, Malterud and Midtgarten (2009). Their acronym EPICURE, which informed my analytic process and writing, refers to the rigour, depth and reflexivity of Engagement with what is studied; the systematic Process of producing, analysing and preserving research data; and of Interpretation (creating meaning by identifying patterns and describing contexts to understand experiences) self and social-Critique. $\underline{\text { Critique }}$ also relates the Usefulness, Relevance and Ethics of the research to the social and academic arenas. Nordic Journal of Music Therapy recommends keeping these items in mind when writing qualitative research (Gold, 2010).

\section{MY PROCESS OF THEMATIC ANALYSIS}

Data sources were mined for codes, identified through the lens of the research question. Codes were distilled into categories, and finally abstracted into themes. The data analysis process, then, followed a progression from codes to categories to themes, though, as I discuss below, the process was not necessarily linear.

\section{Data sources $\Rightarrow$ CODES $\Rightarrow$ CATEGORIES $\Rightarrow$ THEMES}

Figure 1: Process of thematic analysis

These three distinct and inter-dependant levels of analysis have been likened to "micro-, meso-, and macro-level analyses" (Green, 2008, p. 72). Coding of the data set is related to "micro-"; grouping related codes together into categories as "meso-"; and at "macrolevel analysis" abstracting core concepts of inter-related themes which reflect the whole data set. However, data analysis was not necessarily linear as tasks repeated and levels of analysis occurred simultaneously. Tasks and analysis included description, comparison, categorising and conceptualising (Hennink, Hutter, \& Bailey, 2011) The circular nature of data analysis has been described by Dey as moving up and down an analytical spiral as the analysis is built up (1993, in Hennink et al, ibid).

Undertaking thematic analysis, I adapted the step-by-step process offered by Braun and Clarke (2006).

CODES: I began by reading through all clinical notes, journals and supervision pertaining to the two music groups from April to December, to familiarise myself with the data set. As I read I identified initial codes, by marking with red pen in the margin, the concepts which answered the question: how did music therapy support the children's interactions? For example, the phrase in the data: "turn-taking during slinky song" I marked as: "turn taking", "waiting behaviour" "visual/tactile". I also noted if there was something significant impacting on the group or for a particular child, for example, a visit from the dental nurse, staff away, a change in medication for a child or their intense mood. I noted how I adapted my approach to support a child's inclusion in the group. Coding took a lot of time and concentration, so I spread this task over a few weeks. Carefully coded data is foundational for data analysis (Hennink et al., 2011).

As I moved through the data set, I was able to see meaning more quickly and saw that codes repeated and linked together. Therefore to mitigate looking for codes already 
identified, I went over the data set again, back to front, to attempt to have a fresher look and to ensure codes related to the data. Also, some study days I first randomly selected a passage to check codes while I was less immersed in data. I was aware of my role as interpreter of the data, and the risk of imposing codes on the data (Hennink et al, ibid).

As I identified codes in the data regarding interactions, I was aware of how they were integral to the context of the music group experiences. The term ,thick description” offered by Geertz is inclusive of the context, meaning and nuances of what is described (1973, in Hennink et al, ibid). I kept this in mind as I made comparisons and abstracted concepts during thematic analysis. During the coding process I used sticky notes to mark pages which held clear illustrations of a code in order to describe music group experiences.

CATEGORIES: In this part of the research I was thinking about my identified codes and what they meant. For example, some seemed to be more relevant; some were more related to each other. To clarify my thinking, I began to group codes together under bigger ideas on separate pieces of paper. These became draft categories and as I drew the codes together into categories, I often went back to the data to check meaning of codes. Some codes occurred more often in one data source (for example, ,self doubte and ,staff/child play "ere more common in the afternoon sessions. „Waitingee and „turntakingee occurred more often in the morning sessions.) However, examples of most of the codes occurred in each session. Codes could also fit in more than one category, for example, a code of "distress" went into both categories of "hard work" and "changed technique". Delineation was difficult as I kept seeing interdependent relationships between the categories. Also, each session seemed to be a microcosm of the whole. It was reassuring to read of the importance of holding tensions, inconsistencies and contradictions within and across the data (Braun \& Clarke, 2006).

Categories were formed by looking for essential features, similarities and differences, relationships and patterns in and among the codes (Ely, Vinz, Downing, \& Anzul, 1997). I made decisions about the importance of codes because of the frequent occurrence of a code or because of its significance (Rickson, 2010) in relation to the interactive behaviour of the children.

Developing categories was deductive (led by the research question) and inductive (looking for meaning units that might accurately reflect the phenomena portrayed in my clinical notes.) This dynamic combination of analyses is said to help the researcher "to fully interrogate the data" (Green, 2008).

I continued establishing and reworking the categories, sometimes going back to codes until I felt the process of organising and understanding the data came to a point of saturation (Firmin, 2008). Reading over my codes and categories, and thinking about the whole data, I was essentially seeing the same ideas.

Staying with the process, but changing tack, I reworked categories by drawing sketches, relating ideas (Ansdell \& Pavlicevic, 2001) and created a thematic map (Braun \& Clarke, 2006). I also went back to the data and listed examples. I reached a point where I felt satisfied my categories represented the data. My coded constructs became my study's themes (Firmin, 2008). 
THEMES: The next stage involved reviewing and refinement of themes, on the basis of strength and coherence of categories within a theme, as well as distinction between themes. (Braun and Clarke, 2004).

Starting with a theme which seemed most clear, I wrote up a first draft, and progressed through the candidate themes in the same way. Here I was attempting to identify the essence of each theme which in turn reflected crucial aspects of the data (ibid, 2004). As I wrote drafts, I struggled with my inclination to synthesise and so I kept in mind comments from my supervisor about the value of fragmentary or contradictory results of analysis. Holding together the drive to harmonise through interpretation together with complexity associated with deconstruction of meaning is part of the discussion about hermeneutic research methods (Alvesson \& Sköldberg, 2009). I made a section on „personal journey ${ }^{\text {ee }}$ to be possibly included in the Discussion section, because it came from the process of data analysis and not from the data itself. I strove to be honest to the data, referring back to categories and into random samples from the three sources of data when I felt I was getting lost. Some themes were more clearly delineated. Others were initially very long and had fragments of ideas; some of these were subsumed and others discarded due to repetition. Sometimes I moved parts of categories to where I felt they fit better. Editing, re-writing and formulating each theme took longer than I expected. I felt the need to see the whole. It felt satisfying to draw a diagram which clarified and expressed a dynamic flow of how each theme was in relation to others. I have included the diagram in the appendix.

My analysis was informed by research supervision, by checking in with staff, peer supervision and peer feedback on my coding of clinical notes.

The process of thematic analysis was used to distil the essences of my clinical data collected over ten months, through the lens of my research question. My goal was to investigate and communicate how the children's interactions were supported in the two music groups. 
In regard to confidentiality, all information, clinical notes was kept secure with password on my computer; paper information including journal entries did not identify any persons by name or place. Using a secondary analysis of data research method on previously collected data, helped to keep the division between the roles of therapist and researcher distinct and separate, minimising a conflict of interest between being researcher and therapist, therefore there was a low risk that the supervised research process would interfere with usual therapeutic practice.

In this write up, all names of children, staff and the school have been changed or blocked out to minimise identification, although, in a country with a small population, there is some risk the school could be identified. Consent was sought and received from the school for clinical notes to be subjected to secondary analysis research, and informed consent from staff members and Visiting Music Therapist to refer to their input. I considered consultation with staff about the use of their real names in order to honour their work. Although one staff member stated she did not mind if I used her real name, we realized that doing so would increase the possibility of the children or other staff being identified.

Informed consent was sought from six families and received from the parents of four children. The information and consent forms were given out and received back from staff members to reduce any perceived coercion from myself. With one family, for whom giving written permission has not been part of how this family has communicated since their child has been at this school over the past two years, a staff member discussed the information and requested permission. Consent was given verbally. This was verified by the Head teacher. References to the behaviour of only the five children whose parents gave informed consent have been included in this study. ${ }^{2}$

I have attempted to clarify my own bias/perspective and cultural values.

I read and sought to abide by the Code of Ethics for the practice of Music Therapy in New Zealand (New Zealand Society for Music Therapy, 2006) and the Code of ethical conduct for research, teaching and evaluations involving human participants (Massey University, 2010). This study, guided by Sarah Hoskyns (Director of Music Therapy Dept NZSM) was given ethical approval by Massey University Human Ethics Committee (MUHEC 11/41).

The two information and consent forms can be found in appendix 1 .

\footnotetext{
${ }^{2}$ The study most often refers to the four children with pseudonyms of Liam, Rewa, Susanna and George. There are less references to the fifth child for whom informed consent was given, John, because he participated only in the afternoon music group.
} 
My research question was: How can a music therapy student support interactions of children with autism through two complementary music groups in a special education unit?

Analysis of the data sources identified five themes, described separately, which interrelated and informed each other:

1. Engaging the children through being both accepting and persisting, my being ,in the zone ${ }^{\text {ee }}$ and connecting emotionally.

2. Attending to the individual through an individual greeting, identifying sensory preferences and managing sensitivities within the group.

3. Promoting calm by responding to distress, music choice, and simplifying the sensory environment.

4. Giving new experiences to gain attention and interrupt repetitive behaviours

5. Giving specific form to enable interaction including re-direction, patterns, play forms, inviting initiative and supporting staff-child play.

\section{Layout:}

The text of the Findings will be presented in the following way: the title of theme, a brief summary followed by a table. This displays the sub-themes on the left, which were derived from categories, and on the right are examples of corresponding codes from the data. Sub-themes are described in paragraph form, together with some examples from clinical practice. 
Staff modeled to me acceptance of how a child presented on a given day, and persisting amidst resistance to interaction. My „,being in the zone $e^{\text {ec }}$ described my availability to use music therapy to engage the children, and a vehicle for this was making emotional connections.

\begin{tabular}{|c|c|}
\hline \multicolumn{2}{|r|}{ ENGAGING } \\
\hline Sub-themes: & Codes: \\
\hline $\begin{array}{l}\text { Being Accepting and } \\
\text { persistent }\end{array}$ & $\begin{array}{l}\text { distress, sadness, } \\
\text { tantrums, agitation, moving away, } \\
\text { blocking me, staff dedication, self } \\
\text { doubt. }\end{array}$ \\
\hline Walking in the dark & $\begin{array}{l}\text { messy, low energy, staff } \\
\text { dedication, not knowing what to } \\
\text { do. }\end{array}$ \\
\hline Being ,in the zone & $\begin{array}{l}\text { my being ready, real connections, } \\
\text { worked well. }\end{array}$ \\
\hline $\begin{array}{l}\text { Connecting } \\
\text { emotionally }\end{array}$ & $\begin{array}{l}\text { our play, connecting, endearing, } \\
\text { stayed while leaning on me. }\end{array}$ \\
\hline
\end{tabular}

\section{Being accepting and persistent}

The children generally showed fierce resistance to social interactions. Each child was most often focused and occupied in their preferred solitary play activity. Every group music therapy session there were children who showed various signs of distress, for example, sadness, agitation and tantrums. Although one child had some words, communication was through other sounds and body language. There seemed to be many competing individual needs, mostly for movement or objects, but did not seem to be in relation to anyone else. I had the impression the children did not know how to be in a social group.

I learned from reading that the children's resistance was to be expected, and not necessarily a reason to stop an intervention. One child cried for fourteen morning music group sessions before becoming very attentive and ready to participate. Therefore it was important to keep going, be consistent and persistent. Staff members were role models for me in the way they taught daily life skills, played, set boundaries and redirected behaviour, attended to personal cares and physical safety- loving the children for who they are; working with a child's minimal emotional responsiveness and how a child presented on a given day.

Being accepting and persistent also referred to how I felt about my clinical work. My dominant perceptions of the groups in the first months included varying degrees of chaos and few interactions from the children. Codes of self- doubt referred to in my clinical notes, were for example, (3 April) "what on earth am I doing?" from the 
morning group music therapy, and in the afternoon group music therapy, feeling unconnected "I haven't yet found my ground" (31 April).

Walking in the dark

A staff member's comments about understanding the children were: "we just don't know" (2 May) and "every day is a new day" (19 June). This was somewhat comforting to me as I struggled to bring the children into interactions. Not knowing what I was doing was a very uncomfortable place for me to be and journal entries, particularly in the first four months, regularly expressed self- doubt. An example from June 19:

“....staff said they felt supported, but I feel all at sea. I am just so exhausted/frazzled. The afternoon music feels like sporadic individual sessions in an open classroom..." My initial ideas of what a supportive communal music experience would look like were not realised. The mismatch between my wish and the reality made for a long hour, with me sitting on the music mat and “....the children and staff orbiting me, and me thinking, ,oh god what can I play next? ${ }^{\text {ee }}$ Leaving at the end of the day is a relief, to be in a world where I understood what to do, and how to function; it is relaxing to be away from the demands of the children. Was I asking the impossible?"

Being accepting, and persisting despite ,not knowinge were driven by my understanding about the social core of development, and the deprivation effects of decreased access to interaction. Similarly, I was motivated by my belief that music therapy had the capacity to elicit and support interactions and enhance wellbeing. Getting in touch with why I was doing this work helped me find ways around resistance and obstacles to interaction.

\section{Being in the zone}

Codes of messiness and feeling disconnected contrasted with codes which related to my feeling more confident and inspired by music therapy. The latter were from sessions where I coded "worked well", an "unexpected" interaction happened, or when interactions were "extended". These times within a music group happened more as the year went on. It was as if among the persons present there was another presence of „music possibilities ${ }^{\text {ee }}$ I think this was dependent upon my preparation, mulling over what I thought the children might need, perhaps composing something new, and trusting that I knew the children. Then I was more ready and truly open to relating in music with whatever might present from students or staff. This felt too risky when I felt vulnerable, but when I felt unattached to "outcomes" I felt competent to put out more feelers to draw the children in and be more responsive to their behaviours (Aug 4). When I felt ready, or "in the zone," I was more able to intuit and give more towards what was needed to support interactions.

The children's focus and determination was a clear feature of behaviour I observed. This complicated my not understanding about my group members ${ }^{\text {ee }}$ capacity to interact I was not sure if a child may be capable of something but he or she may not want to do it at that time; or the converse - wanting to do something but not being capable. It felt very confusing..... The key question in my planning was: how to motivate children to interact? Emotional connection was one avenue. 


\section{Connecting emotionally}

When a staff member described a parent's grief that their child would not reach typical milestones (April 31), I wondered also about the grief for families of unreciprocated love and attention. Each day I noticed parents ${ }^{\text {ee }}$ warmth and their child seeming to ignore the greeting. Again, staff members were role models for me in the way they loved the children for who they are; accepting minimal emotional responsiveness.

I worked hard to get to know and build on a child's ways make connections. Therefore I was alert and very attentive to any interaction response from the child, a glance towards me or someone else, change in tempo or quality of playing percussion, change in posture, quality of a vocal sound - to interpret these as communication and use these interaction attempts to further engage with a child emotionally. I made an effort to consciously and consistently respond with warmth to their initiating interaction with me.

I consciously chose songs with the idea of ,belongingee in both morning and afternoon music groups. For example, "The More We Get Together"; the Barney song: "I love you, you love me"; "you are my sunshine"; "kia ora whanau" which was a song where I counted and named who is present here today,

There were certainly times of emotional responsiveness from the children in the way they were drawn into play, smiles, eye contact and the way they touched me (for example, June 19.) A higher number of codes grouped under "connecting emotionally" came from the afternoon sessions and examples of references to this code were "sweet" referring to a tender, affectionate response and "stayed while leaning on me."

In both music groups, I improvised with a child's communication of how they were feeling, (for example, music which was quiet, sad, frustrated or excited). This seemed to build trust and understanding between us, and I think this was reflected in more or longer times of communicating in music and staying in the group. 
In the music groups, I discovered that establishing connection with an individual and attending to individual sensory preferences were crucial. Increased unaddressed needs led to decreased availability for interaction and destabilised the group. Staff contribution was essential for children's participation.

\begin{tabular}{|l|l|}
\hline \multicolumn{2}{|c|}{ ATTENDING TO THE INDIVIDUAL } \\
Sub-themes: & $\begin{array}{l}\text { Codes: } \\
\text { Individual greeting } \\
\text { responsivity. }\end{array}$ \\
\hline Valuing staff contribution & $\begin{array}{l}\text { Staff support, redirecting, } \\
\text { staff/child one to one } \\
\text { Staff sharing. }\end{array}$ \\
\hline $\begin{array}{l}\text { Identifying individual } \\
\text { sensitivities and preferences }\end{array}$ & $\begin{array}{l}\text { Tuned out, moved away, } \\
\text { enjoyment, peripheral } \\
\text { attention, enthusiasm. }\end{array}$ \\
\hline $\begin{array}{l}\text { Managing sensitivities and } \\
\text { preferences }\end{array}$ & $\begin{array}{l}\text { Sustained attention, hard } \\
\text { work, new material, } \\
\text { vocalising. }\end{array}$ \\
\hline
\end{tabular}

\section{Individual greeting}

Within the morning group, I found the individualised hello song had a significant influence on how well the children attended and their availability for interaction during the session. Usually the refrain was "hello.... how are you today? Hello.....would you like to play?" as I extended the guitar between us and waited for a response. I sometimes made some light small talk, for example "It's so good to see you!" Responses included immediately touching the strings, running their fingers over the guitar keys, exploring the sound hole, eye contact and vocal sounds. When a child did not respond to me immediately, (for example $13^{\text {th }}$ April with Rewa) I waited, re-invited or touched the child's arm until there was a response. The way the child responded conveyed to me how they were in that moment, therefore what I would need to consider in music choices. It also established joint attention. It felt like the single most important thing I did.

Children came to the morning music group individually from other activities, so it also served to engage those who arrived before the others. Because the children in general seemed to enjoy this one-to-one interaction, shown by smiles and responsive gestures, I hoped it might be something they looked forward to and could anticipate. When the children responded more quickly to their greeting, and participated more in group music activities I decided to cut it short to ,save time ${ }^{\text {ee }}$ (May 8). This seemed to have quite a detrimental effect on the rest of the session, so made a point of keeping this special time of one-to-one interaction at the beginning of the morning group. The positive effect of the initial individual greeting continued to be important throughout placement. It 
became such a familiar occurrence that almost any session served to provide example of children waiting, making eye contact, readiness to respond to my greeting and more expressive and longer responses.

\section{Valuing staff contribution}

When I was prompted in my mid-year assessment to pay more attention to staff as group members, I became more aware that staff provided essential scaffolding for the group. Firstly, developmentally the children seemed to need a dyad for interaction, i.e. one-to-one. Liam, in particular, seemed to need an adult relating with him in order to stay in the group; for example, to hold the woodblock while he tapped, to lean on when feeling sad, a rowing partner. (There were many examples of such „Staff one-to-one ${ }^{\text {ee }}$ coding, which occurred every session.) Moments of closeness like this, between a staff member and a child, were lovely to witness. Secondly, staff being supportive of my leading the group, by joining in singing and music play with children, was invaluable to keep the children's attention in the group. For example, George usually sat very close to his teacher, on the floor by her chair. Thirdly, staff members were quick to re-direct a child back to the group or spot potential danger, e.g. a choking hazard Susanna (13 Nov). Re-direction back to the group happened often in morning sessions, and was valuable in assisting the children to follow group norms/expectation for behaviour, for example, staff directed children to be seated to stay in the group; and by interrupting repetitive behaviours in order to be more available for the music experiences. Fourthly, I valued that staff sharing connected us as adults, for example, when Jean asked the meaning of "kia ora" (2 May) or Judith disclosed a significant anniversary (24 Aug). I appreciated expressions of shared care when staff let me know if a child was struggling that day, and when we enjoyed the children's responses, for example "Look at George!"

Inspiration for an original counting song (which became part of the morning repertoire) came from a staff member who came into the Unit some lunch times and greeted us with "Kia ora whanau!" This is a Maori greeting which loosely translates as "Hello to all the family!" There were many times I experienced shared care for the children, for example, when staff and I shared enjoyment of a child's achieving a play interaction, or a child expressing their individuality. When an adult felt tired or frustrated, it was easy to relate to, and it felt like we were all in this together.

\section{Identifying individual preferences and sensitivities}

From the beginning of placement I was interested in sensory based behaviours and their impact on interaction, and by November, I compiled my observations of a child's behaviour into individual "sensory profiles." Adapting Dunn's (1997) conceptual model of sensory processing (in Tomchek and Dunn, 2007) I described a child's particular seeking and avoiding behaviour preferences, added their emotionally expressive behaviours and described their music interactions. Examples of my profiles are in appendix 2. I wished to understand a child's communication and what might bring a child into interaction. For example, to enable interactions with Liam, I found it helpful to use sudden sounds (foot tapping, woodblock, piano chords) calling his name, being in his space, songs familiar to him, joining with him in ball play, bouncing on the trampoline or play with a scarf. Every day he actively sought interaction with me, and the warmth of his smile and his enjoyment when I joined him in a game, I described as 
seeking emotional connection. I thought his sensory seeking was primarily visual and tactile experiences, and he tuned out of interactions when distressed (was this sensory overload?) and when an adult's attention was shared. Unique sensory profiles, emotional connecting behaviours and music interactions indicated a child's interests and strengths gave me a lot to work with in supporting interactions.

An example of identifying a behaviour preference was with Rewa. Often she resisted coming to the morning music group, then ran quickly across the room from us, often hiding herself behind the couch or a screen. Examples of her participation in music was calling out (26 June) throwing a ball into the group (21 Sept) coming in to the group suddenly, grabbing an instrument and retreating (18 Sept). The times she came into the group were to a small space (16 and 23 Oct). Once I became aware of this, I set out chairs around the group as a boundary and made sure the music mat was in close proximity to a corner made by the piano and the door. This was the place she came to most often.

\section{Managing sensory experiences}

It was a judgment call in group music to moderate the use of sensory experiences. For example, robust excited music drew in Rewa, (20 Aug) but was too much for others; strong rhythm alerted George, but when sustained, it became distressing for him (24 Aug). Sensory experiences in music were used as a means to interaction, so, depending on how the children were, they were introduced or taken away to invite or increase engagement behaviours of attending, waiting, listening, self expression and playing together.

In every morning music group there were times when the children seemed to be not attending, and perhaps it was easier for a child to attend while looking somewhere else. Times of engagement were shown by being watchful, eye-contact and happy smiles (most often from George and Liam), being drawn into interactions (Rewa and Susanna), movement and vocal responses within the music activities. Attending behaviours were interspersed between longer times of staying in the group but focus clearly somewhere else. When group music therapy accommodated children's "in" and "out" behaviours, this seemed to enable staying in the social group.

It was an established pattern before my placement that the arrival of the instrument box, and instrument play, signaled the beginning of the morning music group. I wondered if this encouraged a complex sound environment and repetitive play. Over my time at the Unit, I delayed bringing in instruments until the children seemed to need an object to play with to stay in the group.

However, as a first priority I endeavored to engage the children in interpersonal interaction through music using voice, guitar, touch and seated movement.

Acknowledging that interesting sensory objects were more likely to draw a child out of alone play, my next priority was to use one object in a music activity to gain joint attention, for example, a xylophone, a hoop, a large circle of elastic or a parachute. Making sounds on individual instruments was also valuable participation in the group, and I introduced these as a third priority. There were times in November and December 
when the children engaged in the morning structured music group without the use of individual instruments.

I found that sensory preferences could be an incentive to interact. For example, in the afternoon music sessions John was drawn into play with me through his enjoyment of being touched and of word patterns; once he had experienced "1, 2 Buckle my Shoe" with my moving his legs, and "This Little Piggy" on his toes - he smiled, laughed, said a word when I left a gap, and requested the game again. He stayed with me as long as I continued. Touch was an incentive for him to be part of an interaction; once a pattern (and perhaps emotional connection) was established there was potential to support him to become more interactive when I made small adaptations, for example, waiting for his response, changing position, adding new words and new rhymes.

A music game, designed to raise awareness of others, used visual and tactile elements of colour, size and constructing a hoopla-hoop from segments. We held it together singing "Here we are all sitting in a circle" then I lifted it up above the children's heads and asked who would like to be caught. When a child responded, I slipped it over their head and rubbed the hoop against their back. The "caught" child got a back rub while I sung a refrain and maintained a good distance (about one metre) from them on the other side of the hoop. It was big enough for more than one child, and often $p$ initiated this. A staff member and a child could also fit in together, and more than one name was easily incorporated into the song: "Liam and Judith in the circle (x3), won't you be my partner." By December, most children showed longer interest and either initiated or tolerated being in the hoop with another child, allowing for extended time in this tactile and visual activity. Only Susanna did not want to be caught; for her turn I rolled it in front of her and she reached out to touch it.

Examples of interactions in this activity were George wanted to join the segments together to make the hoop, Liam, George, and I holding the circle together with staff, indicating a wish to be caught, George putting himself in the hoop during other child's turn, Liam smiling and looking at staff member in hoop with him, Susanna reaching out to touch hoop, Rewa enticed from the corner to pack up the hoop. 
I sought to promote calm in individuals and the group and because it seemed to be a prerequisite for interactions. It made it possible to have a group focus, to notice how the children were coping and to help the children self regulate. Generally, I promoted calm by simplifying the sensory experiences. Being together in calm was something we could do together as a group. "Being together quietly seemed to be the means to and an indicator of group cohesiveness." Journal entry (Nov 6).

\begin{tabular}{|l|l|}
\hline \multicolumn{2}{|c|}{ PROMOTING CALM } \\
Sub-theme: & Examples of codes: \\
\hline $\begin{array}{l}\text { Soothing response to the } \\
\text { children's distress }\end{array}$ & $\begin{array}{l}\text { Individual contact, chaos, quiet, } \\
\text { attention to me. }\end{array}$ \\
\hline Music choice & $\begin{array}{l}\text { Worked well, gave group focus, } \\
\text { staff singing to children, settling effect, } \\
\text { being together, familiar music. }\end{array}$ \\
\hline $\begin{array}{l}\text { Simplifying the sensory } \\
\text { environment }\end{array}$ & $\begin{array}{l}\text { Waiting, pause, being calm, simplify } \\
\text { reassurance. }\end{array}$ \\
\hline
\end{tabular}

\section{Soothing response to the children's distress}

In the first few weeks of practice at the unit (March-April 2012), my focus in the morning group was to establish calm in response to distressed behaviours. The challenge for me as a new therapist (and I think for all the staff) was that there were so many different energies, children wanting to leave the group, movement, voices, and staff assisting by redirecting children to be part of the group.

My attempts to gain group focus felt ineffective so I began each morning group with individually approaching and greeting each child, and waiting for a response. My thinking was that even if no other interactions happened, one had been achieved. Other children had to wait while this 1-1 interaction took place, and initially this compromised group attention. I don't know if it was because it became a predictable pattern or because of the personal contact but the children generally stayed on the music mat and waited for their turn by May.

Often there was quiet at the end of the individual hello; perhaps a sense of anticipation or readiness. This gave me a lot of confidence about what might be possible in group. My notes suggested that there were more times of attention and participation in the group when I made this initial personal contact with each child. In the quiet that followed the individual greeting, I began softly singing "You are my sunshine", and this together with the personal greeting, became the established beginning of morning group.

Because the effect of quiet in the group was very helpful for the children's participation, it became a specific goal, though not possible every morning session (4 Aug, 17 Oct).

At least one time of quiet was what I was aiming for. My journal entry (5 Sept) included "now I am gaining traction and the group is going somewhere". In September, when 
being together in times of quiet became more established, Staff commented "The groups have been going really well" (21 Sept).

\section{Music choice:}

I found that using simple familiar reassuring music was a primary calming tool. For example "You are my Sunshine" and "My Bonnie lies over the Ocean" (traditional folksongs which I expected were familiar to the adults). The former was like an affectionate singing to the children; it was simple and the words reinforced a caring relationship, which I think served to soothe the children. In fact My Bonnie was later dropped as it did not seem to resonate so well. With this quality of music followed by silence, one seven year old, „George receptive attitude, on 2 and 9 April). This was significant for him being able to stay and participate, because when his distress level became too high, only leaving the room calmed him (24 July).

I soon realised that typical children's songs were mostly too complex to invite the children's participation, although familiar songs were easier for staff participation. For the children, one idea per verse, and few words seemed most appropriate. In an early morning session, for rhythm I chose: "The Grand Old Duke of York" which was too complex for the children (3 April) so it became "Up, up, up and Down, down, down" with a matching pitch and hand movements. The simplicity of the song meant it was easy to change to incorporate a child's response, e.g. "Wiggle you fingers" when George was doing this (30 April).

Another regularly used example of music to reassure and calm was "The OK Song" where I sang a phrase related to what a child was doing, and in their mood. For example on 2 May, I sung "I see Susanna, she's tapping on the floor, and it's OK...." The verse simply repeated the phrase, "it's OK" This did not always work uniformly for reassurance, calm or focus; for example, one child Liam, would become aroused out of rest when his name was called, if it was an unsettled day for him (31 July). Generally it was helpful. For two children in particular, Rewa and Susanna, it facilitated vocal responses. For example, when I sung about Rewa hiding, on 16 Oct she stood up, let herself be seen, made a sound of "ga-ga" and sat down again. Susanna seemed to enjoy her name being sung and often called out in response. Additional musical-therapeutic strategies were the use of lullabies along with rubbing a child's back for those that could tolerate it (Liam, Susanna, Rewa and George). In the afternoon, "Edelweiss" and "It's a Wonderful World" also served this purpose.

\section{Simplifying the sensory environment}

When music became loud, excited or discordant, a child might cover his ears or turn away and George became agitated and lost his attention

Most children responded to a gentle and indirect approach - softly singing, simple guitar picking, my waiting for a response. When I used this approach on (20 June) Liam stopped his individual play and seemed to be listening, and on Aug 4 George stopped crying and was able to stay in the group.

I learned that simplifying the physical environment also had a positive effect on attention and thus interactions in the group. For example, I covered all the toy area with blankets, cleared the floor, hid all balls, and put out the blue music mat. I selected instruments to be included in the instrument box. For example, only one each, no long 
drum sticks (too tempting to flail them - distracting and could hurt another child accidentally) and also to simplify sounds to only tapping wooden instruments, or only bells. I arranged chairs for staff in a semi-circle, to form a „music group place ${ }^{e c}$ in a corner of the classroom. One chair was placed about one metre from the window and piano for Rewa, to enable her to physically be part of the group. I sat on the floor with my guitar and waited for the children to arrive.

Pausing was very important to allow a child time for processing information. Waiting was a key way to encourage a response and seemed to enable participation. Therefore, waiting felt respectful towards the children to enable their access to interaction. It was holding, and accepting longer than expected response time with a positive frame of mind, as if what I am doing now is the most important thing in the world.

Simplifying the music, the sound and the physical environment as well as pausing seemed to promote calm and support the children's interactions.

\section{GIVING NEWNESS}

When coding my clinical notes of the two music therapy groups, mostly the same codes were identified in each session. Sometimes there were small changes or developments, for example, longer joint attention, more times of initiating interaction, new forms of a music activity were created by incorporating responsive behaviour, or more interactive vocalising. "Newness" was a significant code because it was when I noticed a change towards more interaction, or a new interactive behaviour.

\begin{tabular}{|c|c|}
\hline \multicolumn{2}{|c|}{ GIVING NEWNESS } \\
\hline Sub-theme: & Examples of codes: \\
\hline Characteristics of changes & $\begin{array}{l}\text { longer attention, more vocalising, } \\
\text { significant } \\
\text { extension from previous } \\
\text { requesting } \\
\text { initiated physical proximity } \\
\text { newness and sameness }\end{array}$ \\
\hline Using newness to gain attention & $\begin{array}{l}\text { surprise } \\
\text { MTS spontaneous } \\
\text { alerting }\end{array}$ \\
\hline My being ready to give newness & $\begin{array}{l}\text { boring } \\
\text { MTS experimented } \\
\text { stock take }\end{array}$ \\
\hline Interrupting repetitive behaviours & $\begin{array}{l}\text { breaking own pattern } \\
\text { accommodated change to own pattern }\end{array}$ \\
\hline
\end{tabular}




\section{Characteristics of the changes}

Firstly, changes in behaviour towards more interactive behaviours often did not carry over to the next session; a child might show a new (to me) more interactive behaviour one day and not the next. For example, Rewash sustained engagement with me and percussion instruments on (3 April) but not again.

Secondly, skills/accommodation to new ways of playing together in music built slowly over a period of time, much longer than I had expected. I think that keeping things the same was a building block towards new behaviours. For example, I noted a striking change in Susanna's behaviour in the afternoon group (1 Aug) Before this she seemed to be unaffected by afternoon music -i.e. engaged in alone play, sitting apart from others, mouthing and playing with beads, sometimes standing to twirl and move to another part of the room and sit again. When I included her name in a song, she seemed unaffected. So this first time she came and sat next to me, I was surprised and delighted. On following afternoons, I began noticing how she usually stopped her alone play with beads, watched me set out the mat to begin, and almost immediately came to sit next to me. She engaged in "our dialogue" which consisted of me singing her name, her response either verbal or gesture on me or the guitar. She stayed near for a time when my attention moved to another child, moved away to another part of the room, then back again. She also became more insistent on interaction in the morning group, sitting next to me at the beginning, tapping my knee, interacted with me for longer during her greeting, as well as vocalising when invited. In this morning group students were expected to wait for their name to be called in goodbye song before leaving. Although this was not expected of her, I always included her in the same pattern as the others. Twice (4 and 5 Dec) she seemed to wait for her name, and as she left, gave a little flick of her hand towards me. If this was coincidence, I do not know; staff and I enjoyed these moments.

\section{Using newness to gain attention}

I used newness and surprise to gain group attention in the morning music session. The song: "Kia ora whanau, that's family" has an introduction of finger clicks. The first time I did this, (26 June) there seemed to be a stunned silence of attention from the group. Sudden sounds of finger clicks, slapping my thighs, clapping and a hand bell were alerting of attention. As I got to know the children, and they got used to me, I had more confidence to be playful and teasing, for example, tickling with a castanet, and moving away quickly encouraging a child to follow and reach for it (13 Aug).

Clinical notes listed music of the session to help me remember the children's responses. In the morning group I gradually replaced songs used on days the group was led by other staff. I found the most effective music was created specifically for a person or the group and adapted in practice. As the year went on, I used more variety in the choices, order and qualities of music within the frame of the same beginning and ending of the morning group. Although I sometimes relied on something commonly known, like "twinkle twinkle little star" I was proud to realise (20 Aug) the morning music therapy group had reached a point where the repertoire of „our music ${ }^{\text {ee }}$ had grown and took longer than the session time allowed; leaving out something that worked well also created newness. 


\section{My being ready to give newness}

In the first half of the year, my not knowing what to do felt like hard work to engage the children. When I was not feeling confident, I was easily drawn into the child's preference for repetitive play and need for control. The feeling of relief when I gained their attention/engagement prompted me to repeat what had "worked" (codes noting something worked well, memo to self to repeat) but it was never enough to repeat a pattern without being dynamically present myself, noticing and being ready to improvise with the children's responses; whatever behaviour presented on a day. I needed to be new, on the alert and playful, to find new ways to engage their attention and support their responses. There were sections I felt were dull in my clinical notes, which I coded as "boring". Not much seemed to be happening and I felt dissatisfied with the groups; these sections had few notes and not much enthusiasm or wondering. I noticed that when I re-worked goals, took a "check point" to identify where things were at, or had an assessment coming up - these brought about more vitality. This usually resulted in my composing new music for group. I didn't always end up using the music, but doing something new was a way of re-engaging with and progressing the work.

When I was feeling alone in the afternoon music group, like the "tide was going out" (April 17) I identified my feelings of ,abandonment ${ }^{e c}$ and I wondered if this was also how the children might feel, when isolated from connections with others and the world around them. When I saw a child playing in a tactile repetitive way and while watching me from time to time, I wondered if they were asking for me to come and find them in their world, and that they were trapped in theirs.

\section{Interrupting repetitive behaviours}

Being able to "break one's own play pattern" was a code occurring less often than others, but it was the most exciting to me because I interpreted it as an indication of more availability for interaction. Breaking one's own pattern was shown when a child let me influence their repetition, two examples for the afternoon group: (Sept 19) Liam led by the hand to the mini-tramp; I sang to accompany his bouncing and at end of 8 jumps pulled him off balance and he leapt off. He soon anticipated this. Another example is when (7 Nov) Rewa, in constant movement leaned backwards off my knee. I tickled her tummy, brought her back up to sitting and offering her a calm but interesting song, e.g. "Tu ra lura lura" to help her still, listen and take in what I was offering. When she was still, she was more likely to vocalise, which often led to a sound game between us (8 and 28 Aug).

Sometimes I had the feeling Liam and George were expressing "this is what I do now, help me be different". For example, when Liam approached me immediately I came into the room, fetched two balls, smiled, and started dropping them on the guitar - he may have been simply requesting his preferred play with me, but I also wondered if he expected me to challenge him, (as I usually did, to use his hand on the guitar strings or something new) and perhaps he was also communicating he was ready for this.

New music experiences were developed from a particular child's way of interacting, and were often enjoyed by others. For example, George's rocking instigated the popular rowing song (20/3), where children could be in a dyad with an adult and influence the 
rhythm. George seemed to enjoy this movement and Liam seemed to request it at another times by gesture. Susanna's calling out (24 July) was incorporated into "If you're happy and you know it make a sound" and waiting for a child to make a sound. This music activity also easily invited responses from Rewa and George.

\section{GIVING FORM}

In discussion with the Head teacher we understood that the children wanted social interaction, but the pathology of autism made this extremely difficult to access. Therefore, ,giving form " was necessary as a bridge to build connections with the

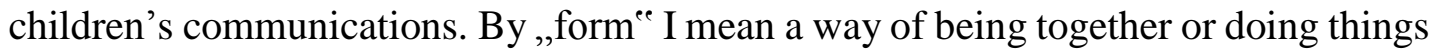
that were predictable and repeatable, like stepping stones, which might give footholds to bring children out of solitary play and into interactions. „Form ${ }^{\text {ee }}$ refers to the external structure of the group, as well as to internal structured interactions. The form I gave to each group had a different effect on supporting interactions. Therefore, in presenting this theme, I will refer to first to the morning structured group and secondly to the free form afternoon music group.

\section{A. THE MORNING STRUCTURED MUSIC GROUP}

\begin{tabular}{|l|l|}
\hline \multicolumn{2}{|c|}{ „GIVING FORM ${ }^{\text {ee }}$ IN THE MORNING STRUCTURED } \\
Subtheme: & \multicolumn{1}{|c|}{ Codes: } \\
\hline Expectations of group behaviour & $\begin{array}{l}\text { Re-direction by staff and } \\
\text { myself } \\
\text { my being clear }\end{array}$ \\
\hline Patterns & $\begin{array}{l}\text { Anticipation, familiar, games, } \\
\text { moment of quiet }\end{array}$ \\
\hline
\end{tabular}

\section{Expectations for behavior}

The morning music group, compulsory for all but one child, had an external form of clear expectations: being in physical proximity to each other, participation, safety, staying for the entire session. There was a clear and regular time and place, beginning and end. Sometimes these were a challenge, for example, George seemed fearful and anxious (March 3, June 6) Susanna stood to leave (March 3, April 4). However, I think clear non-negotiable expectations for group behaviour gave a framework for other supports to the children's interactions, for example, predictability. There was a marked increase in attending and participating behaviours by October. I noted the group felt „easy" to be together. 
Staff reinforced behavior expectations in the morning group by staff redirecting children's attention to music by singing, moving and playing with the children, supporting my lead. Staff gave instruction to sit (immediately the child stood 2 May) and withdrew toys of special interest. For example, when Liam left the group and returned with a ball (19 June). The code of "staff re-directing behavior" occurred daily in my clinical notes of the structured music therapy.

When re-direction was accepted by the child, it increased possibilities for interaction and assisted with self regulation. I will give an example from each of the music groups concerning Liam. In the morning music group (29 June), during percussion instrument play, Liam chose two beaters and repeatedly dropped them on the floor, intensely focused in his own play. When one beater was taken off him, and I held a woodblock near, he tapped, made eye contact, smiled and gently vocalised. In the afternoon group, when there was less form, initiating interactions was encouraged, and at times this behaviour needed to be re-directed. This gave learning opportunities about how to be „next to ${ }^{\text {ee }}$ rather than „on top of ${ }^{\text {ee }}$ the adult. I sometimes needed to discern what the child was asking for, such as play or help to self regulate. In an afternoon session (July 17), Liam approached me. He stood over me, gave me a too tight hug and was laughing intensely. I was afraid I would put my back out. I first tried redirecting him to sit next to me, showing him a way to strum the guitar, singing music he liked. When my assistance for interaction did not help his behaviour, I assisted him to sit next to me, sang and played music I knew was soothing for him, and directed my attention elsewhere. He stayed quietly on the music mat, close to me, listening and sucked his thumb.

\section{Patterns:}

Repeatable patterns were used to increase familiarity and encourage participation. The slinky on elastic was the first original form of patterned music experience, where the slinky passed predictably to the next person. "Kia ora whanau" a song in which we counted and named who is here, also went around the group. Attention to any one child in the group was part of "If you're happy and you know it make a noise" where the child's vocal and movement sounds influenced the rhythm and feel of a verse. Inviting a vocal response was part of the song "here is my mouth, who will sing with me today?" Waiting for a response from anyone in the group, alternated with group focus in a chorus. These patterns formed a predictable sequence where this music would continue until each child had been acknowledged. Some children would contribute for more than one verse. Pairs and the chance to change partners was another pattern, for example, in "Row, row, row your boat." Songs known to adults helped their participation, for example "Twinkle, twinkle little star" and "My eyes are dim I cannot see".

Moments of quiet were also a repeatable pattern, a "form" of being together, and most often occurred at the end of a music activity. When silence happened (more consistently from August) I felt it was important although at first I didn't know why. At the time, I wrote next to this "curious". It wasn't until later in placement that I read its value as expressing a level of contentment, and perhaps a listening or ,digestion "e of what has just happened. By this I mean, the music has stopped and we are still together. It allowed group focus. From then on, I strived to achieve contented listening in quiet together as a sign of and means to group cohesiveness. Although brief, it was a form we could be in together. 
I provided structural support for participation through music experiences and groups processes, for example, pacing the activity, beginnings and endings of music.

Appropriate sensory experiences were also a way of ,giving form "e to interactions, and have been described previously.

\section{B. THE AFTERNOON FREE FORM MUSIC GROUP}

"Giving form ${ }^{\text {ee }}$ in the afternoon music group differed from the morning group. In the afternoons it was not compulsory to sit and engage, and I did not use prepared music games. I provided music for an hour, (which was twice as long as the morning structured group) and improvised with what was happening at the time as a springboard for music interaction experiences. This form eventually allowed for a longer time with individual children when they initiated interaction, which led to individualised ,play forms ${ }^{\text {ee }}$ with the children, movement around the room, parallel play and occasionally interaction between children. Form given in the afternoon music group also to accompanied spontaneous staff-child play.

\begin{tabular}{|l|l|}
\hline \multicolumn{2}{|c|}{ B. „GIVING FORM ${ }^{\text {ee }}$ IN THE AFTERNOON FREE } \\
FORM MUSIC GROUP \\
\hline $\begin{array}{l}\text { Finding our way, few } \\
\text { expectations for group behaviour }\end{array}$ & Difficult, unsure, less form \\
\hline Patterns & $\begin{array}{l}\text { Initiating, play forms, } \\
\text { engagement }\end{array}$ \\
\hline Accompaniment & $\begin{array}{l}\text { Response to distress, staff- } \\
\text { child play, mood, initiating, } \\
\text { surprising, spontaneous, } \\
\text { family lounge, jostling, } \\
\text { parallel play, }\end{array}$ \\
\hline
\end{tabular}

\section{Finding our way}

Initially, I found it difficult to draw the children in to interactions in the afternoon music group. It was probably difficult for the children and staff as well.

Although I was sure about exploring the concept of a free form music group, for most of my placement I didn't feel confident about how to do it; and I think less form made it difficult for me to justify to myself what I was doing. In the first few months of afternoon group, I was tentative, and so were the children who stayed in their own play. My journal often noted "what am I doing here? Is there no form for the children to come in to?" My Visiting Music Therapist advised me to give more, as scaffolding for what the children were giving me. 
Staff stated their appreciation for my "extra pair of hands" at the end of the day and supported by singing along; afternoon session had an increasing number of codes referring to the children who "initiated physical proximity to me" along with "staff play with child"; but my satisfaction with the form evolved slowly. It was new to the Unit and for me; I needed to see ,results ${ }^{\text {ee }}$ of responsiveness and the children needed a long time to get used to a new form. My feelings of "this is difficult" remained until my final month. Positive feedback, for example "I wish you could come every day" from staff, helped change my perspective. This enabled me to move towards a more relaxed "being" together in the form that was created together, rather than what I had originally hoped for.

\section{Patterns:}

In the form I gave to the afternoon group, generally children played alone around the room. Intermittently, one, two or occasionally three children gathered around the adults on the music mat. When a child approached me, we engaged in an extended one-to-one interaction, often to the child's limits (16 Oct). Coded as "our play" I developed individual music play forms with the children. I used movement, rhythm and hand play with George; singing/calling to each other and object play with Susanna; singing, moving and massage with Rewa; ball play developed to play with other objects including instruments, movement and laughing with Liam; rhymes and touch with John. I used playfulness in music as an incentive for a child to initiate interaction.

In the morning group, standing to dance or move around the room seemed to have a disruptive effect on group attention and engagement. In the afternoon group, some children were quite active. There were times when the children allowed the staff and me to move with them in dancing, stamping, bouncing, crawling, playing with a large swiss ball and using a larger space. For example, at the end of the school day, George was usually in movement. When he came and took my hand, we would do a routine of „wash the dishes, dry the dishes, turn the dishes over" where we swung arms and spun around on the last line. Afternoons were often difficult for him when he was tired and his medication was wearing off, and sometimes his movements were agitated. Learning that linear movement was calming, when he requested my attention, and seemed fragile, I walked with him up and down a low bench, stamping, and raising of our arms together at the end, accompanied by a rhythmic verse. This became one of his repeatable play forms which he initiated with me most afternoons.

I was surprised when this served as modeling behaviour for Liam, when in December, he took my hand and led me to the bench requesting this same movement interaction.

\section{Accompaniment:}

However as more children initiated more often, there were less of these extended individual interactions with me and more times that were like a family lounge. A staff member might dance with a child, or a child might come and sit on the lap of a staff member (17 Oct) as we were singing together. Sometimes staff was spontaneous in playful interaction with a child for our entertainment. For example, rock ${ }^{e e}{ }^{\text {ee }}$ roll dancing (7 Aug) or rolling on the floor (24 Oct) It felt good to laugh together. Upbeat music, and group singing, such as „Don’t Worry, Be Happy” or “Ob-la-di, Ob-la-da”, seemed to be 
the most supportive for freer spontaneous adult/child play. It was also typical that children were more settled in their own space/play around the room, and quieter staffchild play was also supported in music. On Nov 21, during afternoon music, when Rewa and a staff member were drawing quietly at a table near the music mat, I noticed her put out her hand towards the adult, who responded in kind. I sang and accompanied their hand gesture. Rewa looked at me and at the staff member; they shared a smile and a short ,hand-dance ee interaction, unusually well regulated by the child, before she returned to her drawing.

Adults singing together seemed to make a "place" for the children to gravitate to or around, to seek adult attention and to engage in parallel play. John's most direct initiative towards interaction was to hide his face in cushions and project his feet towards me (Nov 20). More often he hovered near while vocalizing and seemed to be with the music in his singing $(17$ Oct). A kazoo or castanet also allowed a child to play around the room and indirectly be part of music making (14 Nov).

There were occasional signs of interaction between children in the afternoon group, for example, when more than one child approached me for play and I tried to direct attention to each other. On 23 Oct, George and Liam each took one of my hands requesting movement. As I sang about the three of us, Liam reached out to touch George's red sweater. Sometimes the children competed for my attention jostling or pushing each other out of the way Liam and Rewa (21 Sept). George and John both wanting to be in the ,do-nut ${ }^{e c}$ foam was a source of conflict, but I think my music accompaniment distracted them from their frustration and enabled them to lean on each other for a short time. I felt any interaction involving another child was a positive development.

Most days in afternoon group, at least one child was fragile or subdued. Music given at these times was reassuring calming music in order to hold things together in an even, if low, mood; for example, "Edelweiss" or the "It's OK" song. 
The aim of this study was to investigate how two music therapy groups in a special education unit supported the interactions of children with autism. Analysis of clinical notes identified supportive interventions within five themes: Engaging emotionally, Attending to the individual within the group, Promoting calm, Giving new experiences and Giving form, which refers to structured patterns for interaction, as well as to the frame of the group.

Autism is considered to be a developmental disability, which has implications for early intervention and for influencing the social and physical environments of children with autism (Whitman and De Witt, 2011). It implies that specific interventions are needed for a child's learning and development. Physically the children in this study matured typically, but the impact of autism, difficulties in sensory processing and sensory integration have prevented a child from taking up all the learning and development opportunities provided for them, hence, their development path has many and significant obstacles.

Generally, the children's intermittent interactions needed sensitive and structured supports from an interested adult. The social context and dynamics of the music therapy groups, with teachers and integrated into the school day, also contributed to supporting interactions. I will discuss the findings in a developmental perspective, in sections relating to

a) Early communication and connecting emotionally with a supportive adult

b) Managing sensory preferences

c) Structured forms of support

d) Social context

The interplay of these features were important to support the children's interactions in the two music groups.

\section{a) Early communication and connecting emotionally with a supportive adult.}

During analysis I realised the significance of the support given to the children through the individual greeting, the presence of staff and the extended individual music play times with a child in the afternoon music therapy group. Vygotsky's "zone of proximal development" describes that within a child's developmental level, a child can do more with support than alone. Collaboration with a supportive adult can facilitate the child using their capacities or applying them to new situations (Miller, 2011).

Voice and guitar became my main instruments. These felt like vehicles of direct emotional communication. In singing I improvised with sounds to encourage vocalising. Guitar was both percussive and melodic, and an accessible instrument for the children to make shared music. Inviting touch by extending my open hands towards 
a child, moving together expressively as the child allowed me felt like emotional accompaniment to support interactions.

There is a social core of development, as identified by Shoemark (2009). Concepts of "attuning to" and learning to read availability for interaction, developed in her work with medically fragile neonates, have application here. Although there are many ways these groups of children are not alike, both babies born before full term and these children with autism were non-verbal, had little control over their environment and were in need of support for sensitive neurology. In her study, Shoemark described how the premature baby was drawn into interaction through a relationship with a music therapist attuned to the child's responses and availability. Music therapy intervention promoted development in other domains.

The physical appearance of the children (aged between five and ten, some looked a year or two older than they were, they were strong and moved easily) together with some learned social behaviours, belied that the children's interaction abilities were more at the developmental stage of a young child. In August, when I was becoming more confident about knowing the children, I began to approach afternoon interactions at a more foundational level, and this seemed to be more satisfying for the children (for example, playing peek-a-boo, tickling rhymes, simple finger-play).

Musical interactions form the basis of early infant-adult play. The adult successfully „reads "e and reflects back to the baby; and the child is able to be drawn into emotional connection in which to express needs, learn to communicate, and self-regulate. Inherent in infant-adult play are relational and emotional aspects, and these are specifically used to engender relatedness in improvisational music therapy (Kim et al., 2009).

Early child-adult play interactions of eliciting emotional responses, using simple patterns, repetition, playing with vocal sounds, touch and movement were identified in the Findings as supporting interactions of the children. Concepts of Stern's ,,affect attunement ${ }^{\text {ee }}$ (central to mother-infant communication), Winnicott's play theories and Nordoff-Robbins theory of meeting the "music child" in music work and play have been acknowledged as underpinning group music therapy with children with autism (Tyler, 2002; (Nienhuis, 2005); O’Connor, 2005; Stewart 2002; Goodman, 2007). Interacting close to a child's own developmental play level, rather than chronological age level, was important in order to build confidence and mutuality in relating. Drawing a child into emotional engagement through music influences a child with autism to act (Goodman, 2007).

A vehicle for emotional connecting, in order to bring the child out of seeking solitary experiences and into interaction, was the children's body language and natural frequent physical movement. A way to describe my music therapy approach, which developed over the ten months, was a three- fold pattern of Notice-Invite-Respond. This refers to my Noticing how a child is presenting, use this to Invite a response to music, myself or an object, and Respond to the child's response. This served to support the possibility (keep momentum) for interaction. Music activities were selected to move the child from distress to calm, from calm towards reciprocity, to extend how long they could stay in interaction with support, and sometimes to challenge into new ways of being in interaction, where I expected resistance. It was like a dance where there was a lot at 
stake; sometimes I needed to be accepting of tenuous responses and to appear nonchalant to reduce pressure, for example, with Susanna and John; whereas Liam, George and Rewa seemed to enjoy more active responses from me.

Supporting the children's interactions in the music groups, my first priority was direct emotional engagement of the children (with me and staff) through voice, touch and movement; secondly, through the use of a shared instrument or object, and thirdly through individual instrument play contributing to group music. By the end of the year, the children twice engaged in the morning music group without the use of individual instruments.

Considering the importance of social interaction in education (Bevan-Brown, CarrollLind, Kearney and Sutherland, 2008) and the child's developmental level for interaction, I could have been more conscious of enhancing relationships between children and staff who stay with the child throughout their primary schooling. A focus on attachment relationships in group music therapy for children with autism and their families assisted the children's social skills and enhanced family relationships. (Drake, 2008).

\section{b) Managing sensory processing}

When children are impacted by autism, capacities to interact are compromised by sensory seeking and avoiding behaviours. These behaviours serve an important purpose for an individual's unique sensory processing, which can be hyper-alert, underresponsive and a mixture of both among the seven identified sensory processing systems. Sensory processing, the way a person pays attention to, receives, interprets, and integrates and responds to sensory input, also impacts on cognitive and emotional functioning. The association of sensory processing impairments with autism has been well documented. The purpose of understanding sensory processing differences for this study was to attend to the child's immediate sensory needs, to calm and reduce perceived threats from the environment. Further, it was important to appreciate and be open to ongoing learning about each child's way of relating in order to invite and sustain engagement. Moderating the music environment to accommodate sensitivities and secondly, attuning to unique sensory preferences in order to invite and sustain interactions, guided my music choices and facilitation of the groups.

Promoting calm and simplifying the sensory environment often served to keep a child in interaction for longer. The TEACCH system, employed in the Unit, uses visual prompts. These reduce perceived pressure and simplify expectations or requests by removing emotional interaction, sound or facial expressions which are simultaneously conveyed in verbal instructions. Being together in quiet often happened at the end of a music activity, and felt significant for group cohesion.

Pausing and allowing for times of peripheral attending also served to support interactions in the music groups. In the morning music groups, it seemed that intermittent attention to an individual, for example during turn taking, supported behaviours of watching, waiting, and anticipating. In the afternoon music group, children would move away and at times return. Times of withdrawal and being quietly 
occupied alone were perhaps necessary to enable a child to stay in a group, and often were followed by re-engagement.

In both groups it took some children several weeks for engagement in a new activity. Building trust and familiarity with the way things are done can enable engagement and participation. Allowing a longer time period, months rather than weeks, or more frequent intervention is an important consideration for interventions to support children with autism, compared to children of the same age. It has been pointed out to me that an international study on the frequency of music therapy with children with autism is currently being undertaken. ${ }^{3}$

Facilitating the music groups involved moderating the sensory music environment, as I have described, and simultaneously attending to individual sensory processing needs within the group. I carefully observed an individual child's sensory preferences ${ }^{4}$ and adjusted music play experiences to help a child towards a state of optimum arousal. By this I mean a child's own way of being calm and alert, and more likely to be available for the hard work of interacting. On any given day, this was more and less possible, and I sought to accompany or interact as they were able/allowed me to.

Being in movement with a child's responses to maintaining an optimum state of arousal, is known as sensory modulation (Goodman, 2007). At times I had a picture in my mind of connection through shadowing the movement of the child. No matter what they did, I was consciously connected with them. "Notice, invite, respond to the child's response" was my attitude leading the music groups - I was carefully monitoring the children for signs of distress and for signs of interest, communication, self expression, participating and initiating behaviours. These were the indicators for me to give more or a different form, to play with their response, when to let them have a break, when to invite back in, challenge or support. Improvisational music therapy is a musical attunement process which includes matching movement and pulse to empathetically tune in and create music communication (Kim et al., 2009).

I consciously used sensory preferences to draw a child into a music game, for example, in the afternoon music group with John, I used touch and rhyme. Once the child was responding, I made adaptations to the child's limit. In the morning music group, the hoop, the slinky were incentives to engage in the group music activity. Attending to sensory preferences may help a child to process experiences of music interactions in a way that is "meaningful" to them; not philosophically, but experiencing pleasure, connecting or competence, for example.

Times of extended one-to-one play, incorporating a child's sensory preferences and communication style, were coded as "our play" and occurred more often in the afternoon music group. According to Holck (2004) "play forms" create a context for interactions with those whose communications might be difficult to understand. Creating play patterns, playing alongside, interrupting a child's pattern by making adaptations to give

\footnotetext{
${ }^{3}$ An international RCT study comparing weekly music therapy interventions with three times a week music therapy interventions with similar young children with autistic spectrum disorder. Time-A project led by Christian Gold, University of Bergen, Norway. (External examiner's report, 3 March, 2013)

${ }^{4}$ My observations of sensory preferences and emotional responses are in appendix 2.
} 
new ways to use an object and supporting staff/student play, were strategies used in the music therapy groups. Play is integral to both improvisational music therapy and to early child-adult interactions. Significant play deficits typical in children with autism, the subsequent detrimental impact on learning and development, as well as research which indicates play can be taught and enhanced, underscores the importance of play. Sensory music play was used as an incentive for the child to interact and a way to emotionally connect with each child. Mostly this emotional connection was aimed at a "feeling good" experience or calming/attending to distress. Connectedness and socialisation depend on the body feeling good (Berger, 2002).

Working with a child's sensory processing in order to enhance social-emotional development is part of the Developmental, Individual, Relationship based (DIR) /Floortime approach of Greenspan. The two aspects of this approach are engaging with a child's interests and drawing them into a shared experience to move them up the developmental ladder (Hess, 2012). A music therapy case study with a child with autism is documented by Carpente (2011). It described creating an individually appropriate sensory environment which facilitated the child's ability to self regulate and be available for interactive music experiences. Music play was a means of communication towards a shared experience; where sensory-motor alone play could be transformed into musical interactions.

Music interactions have potential to assist sensory processing, through physical participation, and through the capacity of music therapy to engage the emotions. According to Goodman, this is the key motivation for doing the real work of sensory processing, in order to think and act. When a child with autism has low motivation to engage, their sensory processing abilities can become underutilised (Goodman, 2007). The increase in the children's responses and initiating of interactions perhaps reflected an enjoyment in music which provided motivation to engage and interact (Loth, 2008). When Liam and George ran to me, took my hand or pulled on the guitar when I walked in the door of the Unit, I felt like I was bringing candy.

The therapeutic use of elements of music, (harmony, pitch, dynamics, form, melody and rhythm) can impact on physiology, and regulation of the way a body receives processes and retains information. In an education setting music therapy can promote readiness for learning (Berger, 2009). In the music groups, the children were able to attend, wait and take turns. Helping a child stay regulated and engaged enables learning within the experience, and thus promotes development (Hess, 2012).

\section{c) Structural supports for interactions}

Giving Form was the largest category during analysis. Because the children's clear preference was for solitary play, adults needed to ,give form ${ }^{\text {ee }}$ like a bridge to build a connection with the child's way of communicating, and a pathway for interaction. By "form" I mean structured ways of being together or doing things that were predictable, repeatable and easy to follow. "Form" refers to patterns for interaction as well as the frame of the group.

Giving children with autism supports and structure to interact has an organizing effect, assisting to order some of the confusion and distress associated with impaired sensory 
processing. According to Wigram (2002, p11), for a person with autism, "managing in an unsafe world is the real challenge." This gives another perspective on a commonly held opinion that persons on the autistic spectrum are rigid or fixated. Perhaps it is less about the object or repetition that is sought, i.e. needing to have things the same, and more about the "knowing what to do here" and seeking order when the environment is experienced as overwhelming or under-stimulating.

Patterns gave stepping stones and clarity about what to do. They enabled brief times of group focus and participation and longer times of one-to-one interactions. They needed to be pleasant to draw the child out of alone play, and be like scaffolding in order to sustain interaction. Successive patterns were developed over time from the children's communications, and sometimes developed into play forms. Immediate and personalized improvising in music, also needs form for the child with autism, who typically finds structure difficult to initiate (Goodman, 2007). It was important to write down reminders to myself about the music we had made, in order to give a familiar base for improvisation or to repeat a familiar pattern when a child was losing interest.

Another structural support to interactions was ,re-directing behaviour ${ }^{\text {ce }}$. During placement I saw how a child's ability to accept re-direction, and adaptations to their pattern of behaviour, had a positive effect on their capacity to interact. This varied for a child on a given day. Accepting re-direction is more likely to happen when the child's communication is understood. It is complicated by a person's need to feel in control (Zeedyk, 2008) . High safety needs therefore, also significantly impact on capacities to interact. Rewa, in particular, seemed to need more control over her environment, and it was more difficult to redirect her behaviour when it was inappropriate. Socially this was a big obstacle to her being part of a group. The degree to which a child let me influence their play to new patterns was an indicator to me of how available they were for interaction at that time.

Similarities and differences in the form of the groups contributed to giving the children variety in experiences to support interactions; an enriched environment is widely recommended for children with autism (Whitman and DeWitt, 2012). Music therapy is well placed to provide sensitive and targeted interaction experiences through the flexible use of both improvisation and structured music experiences which simultaneously support and challenge, in order to meet the "complex mixtures" of behaviours of persons with autism (Barnes, 2010). Different frames of each group both supported and challenged the children's capacities to interact.

I will now refer to the table in the Introduction comparing the two music groups.

In the morning music group, structural supports included a contained music place with a room, expectations to sit within the group, focus on myself as leader of the group, staff re-directing attention and withdrawing toys associated with solitary play, group activities using one shared object or instrument, repetition of group games, the individual greeting, and the clear ending. Giving ways to participate included offering choice of object associated with a group activity and the child's choice determined the next music experience, choice of two instruments, and giving a task. 
These structural supports contributed to emergent skills for interactions: most children showed increased times of calm, vocalized responsively, were able to attend for longer periods times, turn-taking, anticipating, initiating interaction, making choices, extended joint attention, and participation in familiar and new music activities.

In December the annual magic show was held in the Unit, and a class of younger children from the mainstream school also came to watch. It was difficult for the children of the Unit to sit and watch, and adults occupied the children to reduce their ,disruptive ${ }^{\text {ee }}$ behavior. It seemed the children were not able to participate by sitting and watching, as did their peers from other classrooms, but seemed to want to participate through movement, and their senses, for example, with touch. Afterwards staff were discussing if it was realistic to expect the children in the Unit to sit for half an hour. The Head Teacher remarked that the children can sit, are engaged and participate in the morning music group.

In contrast, there were less group structures in the afternoon music group. I laid out the blue mat used for the morning group, sat and started by playing guitar and singing familiar songs while children were finishing up a scheduled sensory activity. This was in a large open classroom/play room. Staff members were sometimes attending to other tasks or engaging with an individual and children were free to play around the room. Thus there were many foci of attention and children were not directed to attend to music; the group was less cohesive. When children initiated physical proximity to me or staff, they were invited into music play. In the first few sessions, only Liam approached me for music, but over the following months, all children came in to music. After six months of no initiating interaction with me, Susanna became my most constant „buddy on the mat every afternoon. Longer times of individualised, patterned music interaction with one child occurred compared to the morning group, for all children except Rewa.

Within a form more like a typical playground, spontaneous play interactions occurred between staff and children. On May 30 a staff member played a ,creepy creepy spider ${ }^{\text {ce }}$ game of anticipation and tickling with a child who kept coming back for more. On this day there were two other children from mainstream school present, and the three boys were tumbling together on the floor around the staff member. There were many days when it felt ,messy ${ }^{\text {ee }}$ and it seemed not much communal happened. I don't know if my music connected with the children's solitary play and movement around the room; I speculate that in their heightened sensitivity to what is happening in the room, a child was aware of the music, who was participating in the music, and that they had some influence on the music. There were other days I would describe as a „family lounge feeling: relaxed and fluid, when I felt I was responsive to students and the mood of the group.

My music of accompanying what was happening in the room had more variety and less consistency between sessions, compared to the morning group. In afternoon music, the group could not rely on me to have such a direct initiating role as in the morning group. It was a different focus from me, to give impetus rather than a direct experience for interaction; to reflect back to the group what is happening, to wait and attempt to hold fragments together, working with the interactions which happened. It took a couple of months to establish itself as a predictable „form ${ }^{e e}$. In hindsight, clarifying my purpose and discussing shared leadership with staff would have been beneficial. 
I chose this frame of the group in order to encourage the children's initiative to interact, and to self regulate. By self-regulating I mean the child's self-management within their limits, of being engaged, withdrawing when necessary and re-engagement. This happened most afternoons with George, Susanna and Liam. I knew initiating and selfregulating were hard work for the children. The concept of children's work in therapy is described by Nordoff and Robbins (1971) in Tyler (1988). Giving opportunities to initiate assists participation, along with structured supports (Wolfberg and Schuler, 1993, in Mastrangelo, 2009). I felt the afternoon group was closer to the ebb and flow of typical social interactions, in contrast to the „hot-house ex experience of the morning group of structured interactions.

Sharing the locus of control and finding ways to be together, often brief and sometimes extended, felt very different to the morning structured group. A less directive children's group is more difficult to sustain (Grogan and Knak, 2002) but I persevered because initiating behaviours occurred from all the children. The group became less difficult for me when I was able to relax into improvising with what was happening in the room, play with individual children or not, and contribute with familiar songs for staff participation. This moved the attention to the adults and being social. Towards the end of the year when I became more relaxed and sure this gave more impetus for interactions. It became less important to me what form it took - it felt like "this is us and it's OK."

When I finished at the Unit, staff decided to continue in a similar vein in the afternoons before home time, by introducing an interactive story time.

\section{d) Social context}

For the most part, the children's interactions were dependant on an interested adult. Towards the end of the year, most of the children were able to stay in the morning group without distress, and showed times of engagement and participation here for around 25 minutes. This was without direct one-to-one support. (There were usually six to eight children with two or three other staff members.) Other incentives to interactions were probably 1) music experiences which included emotional connecting and sensory preferences 2) familiarity with me and 3) predictable patterns and forms which gave scaffolding to the children's communications. However, for both groups I could say the whole was greater than the sum of its parts. I have identified „parts of „1), 2) and 3) as supporting the intermittent and fragmentary interactions of the children. Less easy to describe was the ,whole ${ }^{e e}$ experience, group process and the dynamic interplay between members in the group which supported interactions between us. The morning music group allowed almost the whole class (apart from one child and teacher) to be focused together, and created interactions together. This was a significant achievement for the group; that the children tolerated this, to varying degrees. Adults created a social environment which was inclusive of the children who were our focus. Creating community was found to be essential for eliciting vocal responses among pre-schoolers in a parent and child music group (Hornbach, 2011) .

I learned from and felt supported by the staff. Their support of children in music therapy was crucial. It seemed that on a personal level, there was some mutual development of strengths and resources. Examples of personal communications from staff were "you 
give me ideas" ...."I use the OK song at other times"... In the afternoon music group, staff shared family songs or suggested songs from when their children were young. Working with teachers and a multidisciplinary team, both to resource and collaboratively to meet educational needs of children with autism, has been described by O’Neill (2012).

Music therapy within the class programme, gave transparency and accountability to my work. Music therapy was open to view and the staff was part of it, as participants or observers. However, in hindsight, more clarity and discussion with staff would have enhanced a collaborative way of working.

Other ways that the music therapy groups supported the social context of the Unit were that group music therapy fitted in with the school day, with minimal imposition.

Improvisation is integral to music therapy, and I considered my working with existing ways of doing things in the Unit as improvising with the context. For example, the morning music group was well established, and happened at time of day of more structured learning for the children. The afternoon open music group occurred during a time and place of free play and did not require participation. I took the opportunity to be part of break and lunch times, and class outings. A more contextual approach to music therapy, together with creating new forms when it is relevant and necessary has been recommended (Stige, Ansdell, Elefant and Pavlicevic, 2010).

Interactions between children were rare, and I think this reflected the children's early developmental level, of interaction dependent upon an interested adult. In the morning music group, activities were designed to draw attention to each other in the group, and to encourage peer interaction: for example, my naming, counting and touching the arm of who was present; the use of shared instrument or object; turn-taking; celebrating individual vocal sounds. Children „,bumped into ${ }^{\circ e}$ each other when joining in, there were times of waiting their turn, and allowing the ,slinky"e to slide down the elastic to the next person, and often children put themselves in the hoop when another child was there already. In the afternoon group there was more conflict between children wanting an adults $^{\text {ee }}$ attention or the same piece of equipment, which, although infrequent, it was a change from usually keeping their distance from one another. There were some instances of peer modeling. In the afternoon music group, Liam led me to the bench requesting the play form I had developed with George; Susanna, although not expected to wait for her name to be called before leaving the morning music group, twice seemed to wait and perhaps waved goodbye. Although I can't be sure what the children meant repeating the behaviour of another child, these behaviours could not be "taught" by an adult, and points to the potential of a group to provide peer modeling. Facilitating interactions between children with autism in group music therapy was identified as an ongoing question and need by Barnes (2010).

The two music groups were not always a good match for the children's developmental level for interactions, or the complexity of their sensory processing. While it is important to understanding which characteristics of a child are more compatible with choices in one's approach (Mastrangelo, 2009b) it is also valuable to encourage initiating behaviours. This has been highlighted by Wolfberg and Schuler (1993, ibid.) who recommend the use of variables other than structured support for play interventions for children with autism. Attention to the social context as a means to support 
interactions was unquantifiable, and not without complexity. Within the two music groups, increased responsive behaviours from children with staff indicated to me that this was positive for the children's interactions.

The focus of community music therapy is participation which is part of everyday life, therapeutic, promotes health and social change (Stige and Aaro, 2012). This has some relevance to the afternoon music therapy group which was moving towards supporting relationships and belonging of students and staff in the Unit, collaboration, and enabling the children to participate and contribute to the music in the groups. I am looking forward to working more collaboratively and exploring community music therapy where shared experiences in music promote social connections and thus wellbeing. The many connections to and unique experiences of music, can contribute to original forms reflect who we are in this time and place.

Results aligned with Goodman's suggestions for working with children with autism in music therapy. These include a relationship based approach, encouraging variety, simplifying and prompting, encouraging natural shared communication in music activities and incorporating spontaneous communication of the children (2007, p194).

\section{LIMITATIONS AND RELEVANCE}

Clinical notes were recorded by me and through my interpretation, and my experience as a group member. There were many influences and interactions I missed, in the music therapy groups, which may have been revealed through micro-analysis. The afternoon group used a large space, the children seemed hyper-aware of their environment. Introducing video recording seemed intrusive to the culture of the classroom. In hindsight, I could have made better use of consulting staff, and in particular, clarifying why and what I was doing. I think this would have enhanced the afternoon free music group as well as the potential to resource staff to further use music in the children's education.

In this descriptive, exploratory study I hoped to add to the body of knowledge about music therapy intervention with children with autism. Although specific to these students, my experience, the time and place, what is more personal has potential to have relevance to others.

Becoming aware of how I thought about autism and my values impacted on my approach and what I thought might be possible. My observations, supervised clinical work and research indicated to me that managing sensory processing sensitivities and providing interaction supports are primary needs of children with autism. I came to appreciate a developmental perspective for intervention for the following reasons. The children both sought and showed a clear need for one-to-one attention from an interested adult in order to socialise. The presence of restricted and repetitive behaviours, common to children with autism, is also typical in the first eighteen months 
of life (Leekham, Prior and Uljarevic, 2011). Play experiences, the means and context of children's learning, are compromised by a wide range of difficulties associated with sensory processing difficulties including motor planning, receptive and expressive communication, imitation and observational learning (Mastrangelo, 2009). Ongoing experiences of sensory impairments limit the development of attachment, communication skills and social interaction (Talay-Ongan and Wood, 2000). From a neuro-physiological view, the pathology of autism deprives a child of development opportunities. Interventions which are attuned to a child's interaction capacities, and to a child's specific behaviour can "move a child up the developmental ladder", to use a phrase from Greenspan (Greenspan and Wieder, 1998, in Goodman, 2007).

There is a social core of development (Shoemark, 2009). I interpret challenging behaviours as attempts to meet one's own needs in ways that do not serve an individual or their relationships. Therefore, it is crucial to find ways to enable "successful" social interactive experiences which support motivation to engage with others and the environment, and thus, increases access to learning opportunities.

The importance of social interaction for children's development and wellbeing, together with addressing sensory processing differences shaped my music therapy clinical work.

Music therapy in groups can be relevant to promoting flexibility among children with autism, where ,flexibility ${ }^{\text {ee }}$ means ability to make use of, benefit from and contribute, thus, participate in what is happening in a given situation. Inherent in a therapeutic group is a holding capacity, structures of relating and play. Being creative about managing these can enable participation, and enhance the social relationships of children with autism. This could be particularly beneficial to family groups.

I think music therapy has a significant contribution to make to inter-disciplinary work in the field of sensory integration. It was very useful to me to consider physiological underpinnings of the way a child presented, and to use the elements of music therapeutically to communicate with a child and support their attending and participation in the music groups (Berger, 2009). The potential emotional and physical engagement of a person in music indicates a huge contribution music therapy can make to sensory integration interventions (C. Jamieson, Occupational Therapist, personal communication, $10 \mathrm{Dec}, 2012$ ).

Music therapy groups in the classroom with children and their teachers perhaps increased the possibility that learned interactive behaviours would be used in the classroom at other times. This could be the focus of further studies. 
This research study explored supporting interactions of children with autism in a special education unit, where all children presented with significant obstacles to interaction. Two complementary music therapy groups were developed with children and staff: a morning structured music therapy group and an afternoon group during free play time, with the same children on the same day. The research employed secondary analysis of my clinical notes, documentation of supervision and school staff meetings and a reflexive journal. Consent was sought and received from five families to use their deidentified descriptions of their child's interactive responses in the music therapy groups. Five core themes relating to the nature of support offered to children in music therapy groups were identified: Engaging emotionally, Attending to the individual within the group, Promoting calm, Giving newness and Giving Form. These themes were discussed in a developmental perspective in three interrelated areas: promoting emotional connection, managing sensory processing difficulties and providing structural supports for interaction. Further, music therapy groups integrated into the school day worked towards building a community context to enable access to social interaction.

The two music groups, offered in the morning and afternoon, for two or three days each week, with the same children, offered both frequent and a variety of music therapy experiences. The intermittent nature of the children's interactions influenced engaging the children in increments, often and in various ways. Both the structured and the free form music therapy groups were challenging and supporting for different children in different ways. Some children accessed interaction in the groups more than others.

Similarities between the music groups were the same children and mostly the same adults, whose contribution was essential. The music therapy groups aimed to provide emotional support in both free and structured music play. This included one-to-one interactions, eliciting responses by improvising with the children's movements and vocal sounds, playfulness, sensitivity to an individual's interaction style, music play patterns, and adults socialising.

Early communication between young children and adults is inherently musical and has potential to promote emotional responsivity. Individual attention, singing, touch, movement and repetition were helpful to elicit and sustain responses from the children. These were the basis of individual play forms and group music activities.

Managing the sensory environment impacted on the choice of music experience, to promote calm, to be alerting to gain attention, as well as judicious timing for giving choice of instruments and an object for group focus. The use of quiet and intermittent attention was also a consideration to assist sensory processing and self regulation. Acknowledging the impact of sensory processing difficulties I simply sought to reduce perceived threats from the environment and to appreciate and work with a child's way of communicating.

Patterns of individual music play, using sensory preferences, extended interactions in the free play group music therapy, and, during these times, the children showed more instances of emotional expression. Structured ways of relating in music play within the groups gave necessary supports which allowed for various and changing levels of 
participation. The morning structured group was more directive and resulted in times of more engagement as a group. The afternoon free music group, with less direction resulted in more spontaneous initiating interaction from the children and staff-child play.

Over the ten months of student placement, there was an increase in the amount and variety of the children's interactive behaviours within the two music therapy groups. These included times of engagement, vocalising and non-verbal behaviours of movement, gestures of requesting, expressive and/or rhythmic playing of percussion instruments, eye contact, initiating, smiling, tactile exploring of an instrument, waiting, joint attention, initiating interaction and imitation. It seemed that a benefit of music groups for this population is the group's capacity to accommodate peripheral and intermittent attention. Signs of distress and withdrawing were honoured and often a child was enabled to re-engage.

It felt like an achievement that the class was engaged together; this was dependent upon working collaboratively with staff. The two music groups attempted to provide individual supports within social environments conducive to interaction.

There were times the children clearly enjoyed interaction in the music groups, albeit brief and intermittent. The inherent sensory, emotional-motivational, structural and social aspects of music therapy have great potential to generate interactions and enable children with autism to participate in and contribute to the social group of their class.

The two music therapy groups aimed to give the stuffing, boundaries and backing to form a quilt - bringing together and supporting the children's brief interactions, and creating something both beautiful and useful. 


\section{APPENDICES}

1. Glossary of terms

2. Consent forms

3. Sensory observations and music interactions of the four children

4. Example of coding from data analysis

5. Diagrams:

A perspective on music therapy to support interactions.

Themes identified during data analysis

6. Reflexive process 


\section{SENSORY PROCESSING:}

The way that the nervous system receives, interprets and responds to sensory input (Dunn, 2004).

\section{JOINT ATTENTION:}

An emergent interaction behaviour where two people have attention on the same activity or object.

\section{REFLEXIVITY:}

The process of critical self reflection on one's biases and theoretical dispositions, acknowledging my part in the setting, selection and interpretation of data. (Schwandt, 2007). 


\section{A. Parent information and consent form:}

INFORMATION AND CONSENT FORM - Please keep the first two pages and return the last page

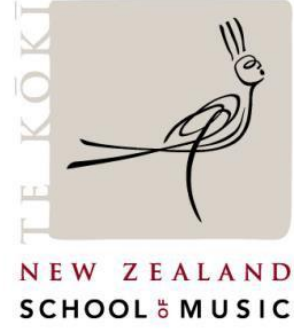

Research topic: Group music therapy to support interactions of children with autism

As you may know, I am a music therapy student working within the School. I have undertaken both individual play and group music therapy with your child. I have thoroughly enjoyed it. As part of my training I am required to look back over the work I have done, and write a research paper on my findings. I am particularly interested in supporting the children's social interactions, so it will include how I have come to know the children, and examples of how the children responded.

I am writing to ask two things:

1. Your permission to include my observations about your child in group music sessions in the research paper.

2. Your permission to talk about your child in group music therapy in my final exam in February 2013. This is a confidential environment with music therapists.

In the writing, there is a slight risk that the children or the school could be identified, because there are few music therapists and students working in Aotearoa/New Zealand. However, all identifying information will be removed from the writing; for example, names of the children will be changed and the school name will be blocked out. I will give you a summary of my findings and I will give a full copy of the research to the Head Teacher A copy will also be held at both Massey and Victoria University Libraries. Perhaps it will be interesting and helpful for parents and staff.

Please feel free to ask any questions - you are welcome to contact me on the above email or phone, talk to staff ............ or my supervisor New Zealand School of Music, Sarah Hoskyns (details below)

If you agree to me writing about your child and discussing their participation in group music therapy at my final exam, please sign the consent form attached, and return by Dec $10^{\text {th }}$. You could send it to school with your child or leave it at the office.

If you give your permission or not, thank you for considering my request. 
This project has been reviewed and approved by the New Zealand School of Music Postgraduate Committee. The Chairs of Massey University Human Ethics and Health and Disability Ethics Committees have given generic approval for music therapy students to conduct studies of this type. The music therapy projects have been judged to be low risk and, consequently, are not separately reviewed by any Human Ethics Committees. The supervisor named below is responsible for the ethical conduct of this research. If you have any concerns about the conduct of this research, please contact the supervisor or, if you wish to raise an issue with someone other than the student or supervisor, please contact Professor John O'Neill, Director, Research Ethics, telephone 06350 5249, e-mail: humanethics@massey.ac.nz

Kate Sanders O'Connor, Music therapy student

Sarah Hoskyns, Supervisor

Associate Professor, Director of Master of Music Therapy Programme

NZSM, PO Box 2332, Wellington 6140 Email: sarah.hoskyns@nzsm.ac.nz 04-463$5233 \times 35807$ 


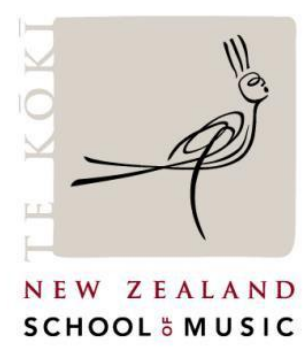

Research question: How can a music therapy student support interactions of children with autism through two complementary music groups in a special education setting?

I have read the information sheet and I understand what it is about YES/NO

I give my permission for Kate Sanders O'Connor, to include examples of my child's participation in group music therapy in her written work YES/NO

I give permission for Kate Sanders O'Connor to include examples of my child's participation in group music therapy in her case study which will be discussed at her exam YES/NO

I understand all identifying details will be blocked out, including names of the children and the school.

YES/NO

I understand I can ask questions at any time to staff YES/NO Kate or her supervisor

I understand Kate will give me a summary of the writing, and the school will have a full copy

YES/NO

NAME

SIGNED

DATE 


\section{B) Staff information and consent}

STAFF INFORMATION AND CONSENT FORM - Please keep the first two pages

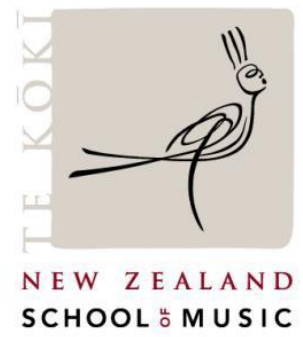

Title of research A playground: Supporting interactions of children with autism through music therapy groups in a special education classroom

As you know, I am a music therapy student working within the .......School. I have thoroughly enjoyed it, and appreciated your input. As part of my training I am required to look back over the clinical notes I have taken after music groups, and write a research paper on my findings. I am particularly interested in supporting the children's social interactions through group music therapy, so it will include references to and perhaps examples of how you supported the children.

I am writing to ask two things:

3. Your permission to include my observations about your input in group music sessions in the research paper.

4. Your permission to talk about your input in group music therapy in my final exam in February 2013. This is a confidential environment with music therapists.

In the writing, there is a slight risk that the school could be identified, because there are few music therapists and students working in Aotearoa/New Zealand. However, all identifying information will be removed from the writing; for example, names of the children and staff will be changed and the school name will be blocked out. I will give you a summary of my findings and I will give a full copy of the research to the Head Teacher. A copy will also be held at both Massey and Victoria University Libraries. Perhaps it will be interesting and helpful for parents and staff.

Please feel free to ask any questions - I am happy to discuss anything at school, or you can contact me on the above email or phone, talk to the Head Teacher or my supervisor New Zealand School of Music, Sarah Hoskyns (details below)

If you agree to me writing about your input and discussing your participation in group music therapy at my final exam, please sign the consent form attached, and return by Dec $10^{\text {th }}$. You could give it to me, Head teacher, or leave it at the office.

If you give your permission or not, thank you for considering my request. 
This project has been reviewed and approved by the New Zealand School of Music Postgraduate Committee. The Chairs of Massey University Human Ethics and Health and Disability Ethics Committees have given generic approval for music therapy students to conduct studies of this type. The music therapy projects have been judged to be low risk and, consequently, are not separately reviewed by any Human Ethics Committees. The supervisor named below is responsible for the ethical conduct of this research. If you have any concerns about the conduct of this research, please contact the supervisor or, if you wish to raise an issue with someone other than the student or supervisor, please contact Professor John O'Neill, Director, Research Ethics, telephone 06350 5249, e-mail: humanethics@massey.ac.nz

Kate Sanders O'Connor, Music therapy student

Sarah Hoskyns, Supervisor

Associate Professor, Director of Master of Music Therapy Programme

NZSM, PO Box 2332, Wellington 6140 Email: sarah.hoskyns@nzsm.ac.nz 04-463$5233 \times 35807$ 


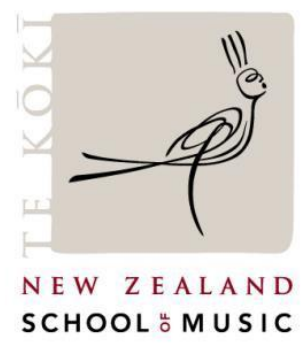

Research question: How can a music therapy student, in two complementary music therapy groups, support social interactions of children with autism?

I have read the information sheet and I understand what it is about YES/NO

I give my permission for Kate Sanders O'Connor, to include examples of my participation in group music therapy in her written work YES/NO

I give permission for Kate Sanders O'Connor to include examples of my participation in group music therapy in her case study which will be discussed at her exam YES/NO

I understand all identifying details will be blocked out, including my name, the names of the children and the school.

YES/NO

I understand I can ask questions at any time to Head teacher Kate or her supervisor YES/NO

I understand Kate will give me a summary of the writing, and the school will have a full copy

YES/NO

NAME

SIGNED

DATE 


\section{APPENDIX 3: SENSORY OBSERVATIONS, EMOTIONAL CONNECTIONS AND MUSIC INTERACTIONS.}

In order to further understand each child's communication, I compiled my observations of the children's behavior in school and in their music interactions. These were developed from Dunn's sensory profiling, (1997, in Tomchek and Dunn, 2007) widely used to appreciate an individual sensory processing, and indicate appropriate intervention for children with autism. Emotional connections were equally important for supporting interactions. Here are my compilations for four children described in this study.

\section{Susanna}

SEEKING/AVOIDING: sought tactile stimulation almost to the exclusion of everything else. She generally avoided being close to people, and sought and maintained her personal space. Therefore it was significant in music when, after six months, she regularly initiated sitting beside me in the afternoon music sessions.

SENSITIVITY HIGH/LOW: I wonder if she had low sensitivities, because I didn't notice dislike of sensory experiences.

TACTILE: mouthing, mouth clicks and raspberry sounds. Tapped on the floor and on herself, and sometimes on me, swirled buttons on a string, rolling on cushions. She made a clear choice when offered two hand instruments and played briefly.

AUDITORY: calling out, vocalised a "wash -oo" sound, responded to my singing her name and waiting for her response like conversation music play. When we sang ,if you're happy and you know it make a noise ${ }^{e e}$ Susanna was the most responsive.

Sometimes her vocalising seemed to be in accompaniment to my singing and guitar.

VESTIBULAR: she had a lovely twirling movement in standing.

ATTENDING BEHAVIOUR: face up, smiling, stopping own solitary movement, watching, physical proximity, initiating touch to another person, vocalising in response like a conversation.

AVOIDED/SELF REGULATION: when Susanna had enough interaction, she went back to her solitary play, flung herself away from me onto cushions or walked away.

MUSIC AND EMOTIONAL CONNECTION: Susanna's conversations I found delightful, and by term four she stayed longer beside me and in our "singing conversations." By August, in the afternoon free music group, Susanna was my most constant companion; several times each afternoon she chose to sit beside me, left and returned. When I was setting up, she often watched me walk past her with the music mat and guitar, and immediately came and sat beside me, sometimes leaned on me. I usually sang her name and incorporated her sound responses into an improvised song, or a familiar song, eg. singing "Susanna" for "Maggie". She seemed to be able to stay longer with pauses in my attention to her, as well as alternating my posture to be sometimes not directly facing her. One afternoon she had moved away from the music 
mat and sat on the mini-tramp. She started making singing noises, face up and smiling. I came and sat beside her and she tolerated my coming into her space and vocalising with me in "our conversation" style. Other times she seemed to be singing along, even when close beside me, but seeming to be not attending, eg. rolling on the floor. When lying on her back and protruded her tummy, I wondered if she wanted me to tickle her. She allowed this briefly. I felt this was a significant playful behaviour. Sometimes I put a toy in her way, for example, the wobbly bell toy that rights itself when knocked over, and also a red medium sized ball. She pushed the toys away, but stayed with me, as we alternated moving the ball/toy. In the morning music group, Susanna increasingly approached me for her individual hello song, was interested in the guitar, and contributed by vocal sounds and floor tapping.

\section{STRENGTHS:}

- Vocalising

- Developing "conversation" when I gave music attention and waited for her response. These included vocals, tapping on an instrument and sometimes on each other. in live music

- Listening and participating

- Initiating interaction

- Choosing between two instruments, choosing to be near music therapy student

\section{Rewa}

Rewa sought play, connection and sensory experiences in a focused way. The first time I met her, she was in the classroom, and distressed; I sang to her in a soothing concerned way, she sat on my knee, and rocked me, leaning back and forth; I sang "waltzing matilda" which became a point of contact between us. She occasionally and briefly sat near and participated in both music groups. During break time, when I approached her in her play activity and played alongside her, she was aware of me and made intermittent eye contact; sometimes she blocked me and sometimes let me join her. The times she was able to stay with me, when I sang to her, she vocalised with me in dialogue, and seemed to enjoy it.

SEEKING/AVOIDING: Generally her behaviour was active and self determined which indicated more sensory seeking than sensory avoiding preferences. She chose many vestibular, tactile experiences, choices also for physical touch and emotional connection; she had quick movements and was often directive in interaction. SENSITIVITY HIGH/LOW: Generally low sensitivity threshold. She could throw herself on the floor in a tantrum and didn't seem hurt; she didn't mind her face, hands, and body messy; she was happy to be half clothed, with bare feet. In one-to-one interaction with me, she often put her face very close to mine. She could engage immediately in social interaction or a new activity.

VESTIBULAR AND PROPRIOCEPTIVE - She often tipped herself upside down, sought the spinning office chair, and the swing. She showed great balance and climbing 
skills, with no fear of heights, for example, putting herself in a precariously high position on stacked chairs to reach a swing that had been placed out of her reach. When interacting with me, she was usually very physical and often tried to pull me off balance; for example, she often ran and jumped on my back, or initiated walking on my feet with her back to me, but she is heavy and I needed to stop before she was ready to stop. She liked to run and move quickly. She often moved in a sudden determined way, eg. ran from one part of the room to another; I did not often observe her walking. She most often went to a corner or edge of the room or directly to get what she is wanting, for example from the fridge.

TACTILE - She showed a preference for focused hand activities eg. sand play, paper rolling, i-pad, and these seem to be calming. Often in our interactions she put her back against me; when she lay on me it seemed like an invitation to massage with deep pressure; she liked me playing with her toes, rubbing her back, pushing her hair out of her face with slow firm movement. She enjoyed physical rough-housing.

MUSIC AND EMOTIONAL CONNECTION - Rewa sought interaction with me in a playful direct way, for example, came and leaned on me. She was often excited and over-reactive physically, for example, climbed on top of me, put her face directly on top of mine. Her smiling, happy face and sounds I found endearing, but sometimes, it felt like she was preventing me from doing anything else. When I approached her and waited for her response, she often took my hand, smiled at me, vocalized. At times she was quite directive and intolerant of my extensions to her interactions and movements, for example, when I directed her to sit next to me, rather than on me, or moving in a direction of my choice. There were times she was responsive in one-to-one interactions, when she played instruments, I incorporated touch or played alongside her.

Rewa attempted to join in the music groups, for example, being close by but in a corner or under something. She sometimes moved into the group but more often added her voice to activities from across the room. At the end of morning music group, when children wait for an individual goodbye before leaving, she often seemed in tension, wanting to leave from her hiding place. She usually left the room running; sometimes managing to wait for her name.

In morning music session she usually went to the edge of room away from group, back to the wall, or behind something and was watchful. She responded to the one-to-one hello song, though not usually immediately, with eye contact, smiling, sounds and touched the guitar. During the group, in response to my including her, she mostly just looked at me from across the room when I invited her to come into group. However she often called out as if to join in or threw a ball into the group, and vocalised when I named her in song. In November during the OK song I sang about her hiding, and she jumped up to be seen and sang. Occasionally she ran into the group, to a place where her back is against the wall, or slightly behind someone, and grabbed a drum, or percussion instrument on which she pounded and vocalized. She once sat in the group at the beginning of the morning session, and stayed for the first half, the longest ever, with my cueing her in with eye contact, smiling, laughing, and with reference to her in vigorous and fun movement activities. 
As the year progressed, she seemed to be making more and different sounds. I wondered if one of her sounds was her repeating her own name. She used the drum and symbol in music group, strummed the guitar when invited and responded used her voice when I sung hello. New activities with instruments or toys usually brought her briefly into the group, along with having a job to do, for example, bringing over the instrument box, tidying the instruments, putting away the hoop. She noticed and responded to new music, and enjoyed the piano sometimes. In one-to-one play she often responded in vocal conversations where I played with her sounds and sang. Often this was when the other children had gone home.

She showed a clear avoidance of sitting in the music group and other physical proximity to another person unless she had initiated it; she sometimes refused tasks initiated by an adult. I wondered about a fear response regarding social interaction, particularly a group. Perhaps her strong will to do things her way reflected this.

A fear response and high safety needs perhaps underpinned her hiding behaviours, sudden movements and determination. Hiding behaviours included: behind her hair, under couch, under blankets, inside the hammock swing. The times with most participation in morning music group was when she came to sit in a corner made by the piano, the window and a chair. In the afternoon group she came close to me by lying under the couch/cushions. Sudden movements included running suddenly from one place in the room to another, towards a definite goal; she did not meander, in a relaxed way as some other children did in free play. She seemed to be watching what was happening in the room when engaged in an activity. Postures that surprised me were preference for a corner or a height, and keeping to edges of the room; even the swing allowed her to look out and keep an eye on what other people are doing. At times she was very determined about the way something was to be done. When prevented from something she wanted to do, she sounded and acted inconsolable, and eventually calmed by doing some favourite activity (eg rolling paper, or smoothing talcum powder on the lino.)

\section{STRENGTHS:}

- NEWNESS/NOVELTY: Rewa was quick to take up new experiences. She enjoyed new activities and instruments in music, for example she joined the music group when slinky song, the bell were first introduced, but only once after. She initiated interactions with teachers and myself who didn't come every day. In the second session of individual music therapy - although she spent the first half hidden in a cupboard, I sung hiding songs and played with her toes that were peeping out, she eventually came and sat with me in middle of room, leaned on me, with her back against me, and explored instruments in my bag. In hindsight, I could have further supported her interactions by providing more new experiences, along with more individual sessions which gradually might include others.

- Focused and determined. She sometimes pushed me away when I tried to guide her problem solving. There was an immediacy to her behavior.

- Physically adept with very good eye-hand coordination 
- Having a task gave her focus to interact and be in the music groups, for example, putting the hoop together, packing up the instrument box. Once when I told her I was leaving, she got my bag and led me to the door!

- Vibrant combination of energetic personality and movement, seeking activity and pushing boundaries, seemed to enjoy being competent.

\section{Liam}

My first contact with Liam was to approach him in play when he was repetitively dropping two balls on the lino and catching them again. When I sung accompanying his movements, he smiled and looked at me each time he caught the ball, and sometimes made a happy "ee" sound. My interaction seemed to keep him more in this activity, because he seemed to find it more fun than when I had been watching him play alone from across the room. After this encounter, he always approached me when I came into the room, smiling, and took my hands, as if inviting me to play.

SEEKING/AVOIDING: generally more tactile, visual and vestibular seeking than avoiding behaviours.

HIGH/LOW SENSITIVITY: generally moderate.

VISUAL/AUDITORY: I think the ball dropping preference was a visual stimulation, also auditory as he preferred to bounce the balls on the lino rather than the carpet; and also in music group, he liked to pick up and drop drum sticks on the floor.

VESTIBULAR: He enjoyed bouncing on the mini-tramp and swiss ball (and I usually changed or moved away before he was ready for me to stop, because it became too repetitive.) He initiated this contact with me enthusiastically. He thoroughly enjoyed the ball-pit, in the snoezelen room.

TACTILE: He liked to sit on my knee. When feeling sad, he often came and leaned on me sucking his thumb, with a soft blanket, cushion or teddy bear - oral stimulation was self soothing. In individual sessions he liked to roam the room touching things. This felt like he was looking for something to engage with. Often he needed something to touch, or an adult to sit with him in order to sit or stay in the morning music group.

MUSIC AND EMOTIONAL CONNECTION: His capacity to pay attention and interact in music depended on how settled he was. When it seemed he was in a resilient space, shown by his being calm, clear eye contact, no distress, he interacted one-to-one for sustained periods of time.

For example, he has sat and engaged for varying lengths of time. In November, while thumb sucking and he dropped a twirled pipe cleaner on a variety of musical instruments (bead drum, hand bells, woodblock and small beater, ukulele) and vocalised in a musical conversation.

He stayed with me making sounds, tapping, dropping, and accommodated new small challenges to our play games. He showed times of contentment with sweet melodic music when he became still, head on the side with a smile, in a listening way. 
In both structured and unstructured music groups, his preference clearly was bouncing a small ball off the guitar strings and catching it. This required good eye-hand coordination because I held the guitar on an angle to change chords, which varied the sound. Although initially insistent on laying the guitar flat on the ground, each time he reluctantly accommodated my variation. With direction, he has used his hands on the strings.

Liam clearly enjoyed interacting with an adult, often initiating interaction. He usually needed this one-to-one attention in order to stay. In early sessions he put his hand on my arm while I tapped a woodblock, then at later music sessions would use the beater independently.

In individual music sessions he imitated my stepping sound on the lino, sometimes extending this; he also responded to my calling him back to the guitar or piano with strong rhythmic chords and singing his name when he wandered off searching around the room. He was also redirected from his alone play when I played the woodblock, invited him to play guitar, sang his name, stamped on the floor and held out my hands inviting him to "dance". At times I let him go, because I was guessing the interaction had become too intense. I tried to finish the session before it seemed like too hard work to re-engage him, and perhaps it was becoming counter-productive.

He played piano briefly in individual sessions, and I usually chose firm clear chords, like gospel music or marching, to match his movement and to gain his attention. The other main type of music I used was lullaby and sweet music; once in individual he leaned on me, sucking his thumb and I sang to him in his blue sweater "little boy blue come blow your horn". He seemed to recognise and calm with familiar music. His vocalising was often an "ee" sound when he was happy and a "ng" sound when out of sorts, or struggling. He took my hands when I offered them for jumping or galloping, and stayed in a song "pop goes the weasel" and seemed to enjoy and anticipate the "pop." I encouraged his making sounds, for example, one sunny day during outside play on the lawn, he made sounds for a sustained period of time when I was singing and teasing Liam with a piece of long grass.

Liam anticipated patterns and imitated another child. For example, after witnessing an interaction with George on the mini-trampoline, he would often lead me there, where he would smile and laugh as he bounced. To extend the activity, the song I sung had a chorus, when I would guide him off the trampoline with a jump. He soon anticipated this. Once when walking with another child up and down the low bench, he took my hand as if to request the same activity. At the end of the end of the bench, I led him into a jump off, and he soon repeated this pattern of walking and jumping off.

Liam almost immediately approached me with smiles when I walked into the Unit. The magic memories I have of Liam are when he freely gave me his ball and we bounced it between us, and the times when he "sang" along with me.

SELF REGULATION: He could be compliant, and re-directed and not always insistent on getting his own way. When unsettled, soothing music and indirect attention seemed helpful to him. For example, during times of distress he sometimes came near me and grabbed my neck or hair. It felt like he was seeking understanding or help to feel better, 
but his agitation made him be "rough". Towards the end of the year, he was able to stop himself when I have been reassuring.

\section{STRENGTHS}

- Emotional connection through physical play and making sounds

- Initiating interaction, vocalising and staying with an adult

- Physical coordination, eye hand coordination

- Self regulation - sometimes he self-soothed, and could approach an adult for help. Accepted adult re-direction and instructions

- Enjoyed music

- Pleasant personality, smiled easily

- Anticipated music and movement patterns

- Responsive to rhythm and playful sounds.

- Waiting and turn-taking

- Some awareness of others shown by requesting another child's music play pattern

\section{George}

SEEKING/AVOIDING: mostly seeking vestibular and tactile stimulation.

HIGH/LOW SENSITIVITY: high sensitivity to sound and overload; perhaps low sensitivity to tactile and vestibular (he seemed to needed a lot of this).

VESTIBULAR and PROPRIOCEPTIVE: very active movement - running across the room and in the playground; also galloping and sometimes crawling, sometimes briefly chose the mini-tramp to bounce. His rocking side to side movement in music initiated the popular "row row row your boat" activity. He was able to do a repeating, ,airplane move $^{e e}$ on a swiss ball where he threw his tummy onto the large ball, balanced his hands on the floor and raised his feet almost to a handstand. The movements he chose are known to be calming to the vestibular system.

TACTILE - often objects were mouthed. He touched the guitar strings and wood. Our music play games included my touching his fingers individually with a rhyme, and a high five at the end. He would often extend his fingers towards me as if asking for hand interaction; I used finger play rhymes to engage him. Sometimes I rubbed his back when he came to sit next to me.

VISUAL AND TACTILE- he liked to twirl cords, turn on the tap and splash water, muss up the plastic pages of my folder.

AUDITORY - calmed with silence and quiet music. Sometimes enjoyed rhythmic music, but at times this would be followed by distress. 
MUSIC/EMOTIONAL CONNECTION - George was quiet, watchful and still when ready for interactions. This was his usual behaviour at the beginning of the morning music group, when I sung hello to each child. At theses times, George often sat partially behind his teacher aide, watching and waiting for his turn. I gently invited him to play guitar and waited; in his own time he explored through touching, kept eye contact and smiled. He seemed to be most responsive with quiet and familiar music. He seemed very attached to own teacher aide. He often made requests by taking a staff member by the hand and led them to a door; he loved to run outside. He approached me several times a day as if requesting to play. He sometimes searched in my pocket and found the toy for the next music activity. In music, he often vocalised an "ee" sound when he was happy, and when invited to sing. He used beaters on drums and tambourines, played with bells, rocked in time with singing and ,rowed "e with an adult partner. George took turns with other children in the slinky song, was happy to be "caught" in the hoop when we sang to him, and sometimes initiated this.

His seeking of movement in the afternoon music groups often instigated our hand swinging rhyme of "wash the dishes, dry the dishes, turn the dishes over". Another pattern he often requested was my singing and stamping to accompany his walking along the low bench and when he reached the end, raising and lowering our arms together. He became more actively involved in the changes.

SELF REGULATION: Movement was very important, and he often sought it for himself. When mildly distressed, sometimes George would approach an adult, as if for help. I found attention to his hands was soothing or perhaps gave him the interaction he was seeking. When very distressed, George made eye contact but it seemed tactile pressure without my voice, with my gaze averted, that is, less stimulation, helped to calm him. Occasionally George could not settle in the morning music group, and needed to leave. Linear movements are known to be calming - one afternoon, after noticing George becoming unsettled, I approached him and we calmly walked together up and down a wooden bench. Following this, he put himself into the large donut with only his head visible, looking out on the room and still, as if self calming, until it was time to go home. Sometimes engaging in vigorous activity seemed to escalate into agitation. In the afternoon free music making group, George often came and left. Mostly it seemed he needed to move. Percussion was too alerting; melodic music along with finger play and rhymes helped him stay in movement activity, along with periods of calm and brief vigorous music interaction.

\section{STRENGTHS:}

- Movement - strong and well coordinated

- Gentle temperament

- Initiating. Sought interaction and can sustain joint attention with a toy or instrument or movement

- Quick to notice things that interested him

- Self regulation, sought vestibular activity 
Here is an example of how I coded notes from the morning structured music therapy group of October $31^{\text {st }}$. Only references to children whose parents gave informed consent have been included. Codes are indicated by $\wedge$ and written in italics. My wondering about what the behaviour meant also included.

Impression of group: Seemed to respond to quietness/calm/reassurance/order today. Times of pausing. I commented: "what a nice group of friends here today" ^MTS calming/reassurance/reflecting back to group what is happening.

Pregroup: new song: "sometimes good enough will have to do $\mathrm{x} 2$ when you've done your best, you can leave the rest, oh, sometimes, good enough will have to do." ${ }^{\prime} M T S$ intentionally available to use music therapy, being in the zone

At school, Rewa distressed, Liam high mood, George next to me, on verge of losing it. $\wedge 3$ children distressed

What happened:

1. Individual hello - I was very relaxed about this. $\wedge 1-1$ initial connection

2. You are my sunshine $\wedge$ familiar ${ }^{\wedge}$ staff sang to children

In response to Rewa screaming:

3. OK song ^reassurance

4. Row row row your boat $\wedge$ movement in partners $\wedge$ familiar

5. School song with slinky on elastic $\wedge$ familiar $\wedge$ group awareness

6. 'Kia ora whanau' counting song ^familiar ^group awareness

7. Instruments - the children's offerings seemed accidental. Staff: resonant sound on drum/tambourine and clapping incorporated into song. Interspersed with quiet for George and Liam. $\wedge$ staff $x 2$ initiated robust rhythm ^quiet for $3 \mathrm{chn}$

8. „Here is my mouth, who will make a sound.....? ^eliciting sounds

9. „Here we are all sitting in a circle” with hoop ^group awareness ^joint attention $\wedge$ turntaking $\wedge$ initiating

10. Twinkle twinkle $\wedge$ quiet $\wedge$ calm unifying

11. Goodbye song ^pattern ^individual

GEORGE- sat next to me, eye contact, hand on guitar for hello song; ^one-to-one responsive; Twiddled with guitar keys, told $\mathrm{NO}$ by staff $\wedge$ redirecting(is twiddling an effort to self calm or shows he is getting worked up) Rowing: one hand on me, arm straight, eye contact, smiling; repeat: other hand but less engaged. ${ }^{\wedge}$ vestibular/engaged Pulled slinky out of my pocket. ^initiating, anticipating. After slinky away, pulled it out to twirl elastic, became upset when couldn't have it, and stayed a little distressed until end of group. Attention for counting song, moving attention around group. ${ }^{\wedge}$ watching behaviour, attention during familiar pattern, Also during hoop song. A little crying $\wedge$ distress. Instruments - played beater on tambourine briefly, was subdued; ${ }^{\wedge}$ self 
calming. Goodbye song MTS: have you had enough, George? You can go; I called his name first. ^attending to individual needs

Initiated physical proximity (ipp) ^ initiated and responded with communication $\wedge$ accepted redirection ${ }^{\wedge}$ group norm ${ }^{\wedge}$ regulate self to group norm with adult direction $\wedge$ practice in $\wedge^{\wedge}$ interactions through nonverbal communications elicited $*$ interactions ....invited to extend *place for supported interactions *place where interactions are celebrated $\wedge^{\wedge}$ public place of social group ${ }^{\wedge}$ public acknowledgement of child $\wedge^{\wedge}$ supported natural environment ${ }^{\wedge}$ child is part of a process -rather than being focus of attentionattention of adults shared more like a family where siblings need support to be there part of it, but child is not the whole of it - individual MT child is focus, GMT focus is child and process - shared attention from adults- spontaneous interactions can happen

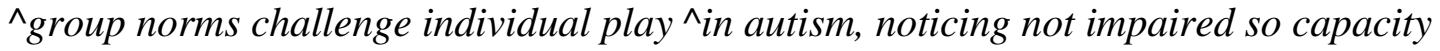
for group experience available, albeit less participatory than typically developing peers $\wedge$ all going in, difficulty coming out/expressive interaction ^lots of appropriate supportive input from adults and process to assist child to output and interact ${ }^{\wedge} c f$ motivation to engage, to output, build success in $\wedge$ in autism is there a block to output, to express self - creativity and play to assist this ^ how do I engage with the world? Teach it, practice, stepping stones - paralysed by notable to access interactions - therefore choose own company, but still have need to feel belonging ^adults sensitive to what child can tolerate, adjust, be flexible ^group norms are outside the child - child has to conform to an outer expectation which challenges and develops abilities

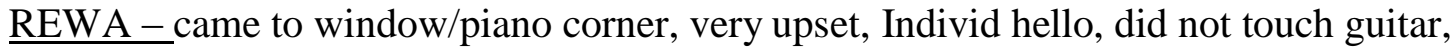
looked at me, I spoke/sung in a soothing way, and rubbed her back. Wanted swing, staff: NO. Went to balls in corner and threw a ball our way. Counted her in song. Watched, made contributing vocal sounds during make a noise; and at to her times during music after she had calmed down. Hoop, would you like to be in the circle? Vocalised "ah ah" looked, came and touched and ran back to corner. When I brought the hoop to her, she seemed unsure, I put it briefly around her, she looked, touched briefly and I withdrew before she could. I asked her to help separate/put it away, she was happy to put the pieces in the bag. Significant: had a job to do. Also, restrained herself from controlling the hoop; watched without disrupting or temper tantrum. At end, when I called her name, she waited, straightened the bells in the instrument box, then left. ${ }^{\wedge}$ (job/her participation) sense of control allowed.

$\wedge$ distress $\wedge$ adult responded to feeling $\wedge$ adult went into child's physical and emotional space and elicited response from child $\wedge$ expected $\wedge^{\wedge}$ child blocked from what wantedadult gave limit to child, enforced group norm ${ }^{\wedge}$ child accepted $\wedge^{\wedge}$ put object rather than self into group $\wedge$ use of objects -from child; from MTS to enable group participation $\wedge$ familiar activity with particular way to join in ${ }^{\wedge}$ norms

$\wedge^{\wedge}$ roup norms are outside the child $\wedge^{\wedge}$ invite child to behave according to group norm $\wedge$ invite child to participate as they are able, incorporate, enjoy, celebrate, extend their interaction, play/surprise $\wedge^{\wedge}$ for Rewa - give a job, way to participate $\wedge^{\wedge}$ child exercising self regulation $\wedge$ respect autonomy, sense of control

$\underline{\text { LIAM }}$ - on edge at beginning, rowing with staff, hit her in the face, agro/agitated, MTS: Liam, are you feeling sad today? Staff picked up on this; he calmed, was able to stay in, 
for whole group, just sitting, sucking thumb, not seeking balls. Instruments ; 3 drum sticks and watched them fall, looking at me for attention/reassurance/approval. Hit large yellow ball that Rewa threw into group, but only $2 x$, not perseverative. Mood: half hearted, a little despondent. Attentive to me during counting song. In hoop with Staff, he put his arms gently around her neck and smiled.

$\wedge^{\wedge}$ child agitated ${ }^{\wedge} M T S$ responded to feeling $\wedge^{\wedge}$ stayed, allowed self to be calmed and stay in self soothing behaviour, watching, not seeking own play $\wedge$ paying attention $x 3 \wedge$ child outside group threw in a ball, child in group batted it ${ }^{\wedge}$ Rewa's attempt to interact gave opportunity for a response from Liam ^children's interactions/communications also give opportunity/invite interaction ^ groups give many interactive opportunities ^ hoop song - warm towards staff who calmed him earlier ^activity assisted positive child/staff interaction ^challenging for children and need a break afterwards

$\wedge$ did the group experience teach interaction skills?

SUSANNA - clicking sounds during make a noise, very clear, seemed to know. Came in, looked, sat in front of me in a relaxed leaning on me way. Tapped guitar, when Liam commandeered the situation she left to back of mat by the wall, where she often sits. Does a hand movement, like a wave at hip height; when I waved goodbye to her, she turned and did this, vocalising; on her way to morning tea.

$\wedge^{\wedge}$ ipp ^group: this is the time to communicate (interaction) Instrument gave way to communicate $\wedge^{\wedge}$ moved out of pp when another child sought my attention $\wedge^{\wedge}$ child needing 1-1 $1^{\wedge}$ followed other children out of room, did she do this purposefully? modelling

STAFF - contained Liam, actively assisted the children to stay. Firm NO with Rewa. Directives to George, Susanna; Supportive and contributed to music, even though for one staff member English is not strong.

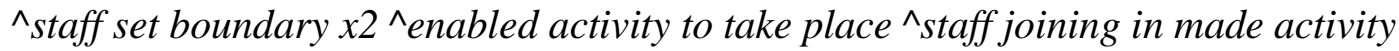
stronger, more for children to respond to, more responsive opportunities for children ${ }^{\wedge}$ staff overcoming barrier ${ }^{\wedge}$ reinforced protocol for children (2) 
A perspective on music therapy to support social interactions:

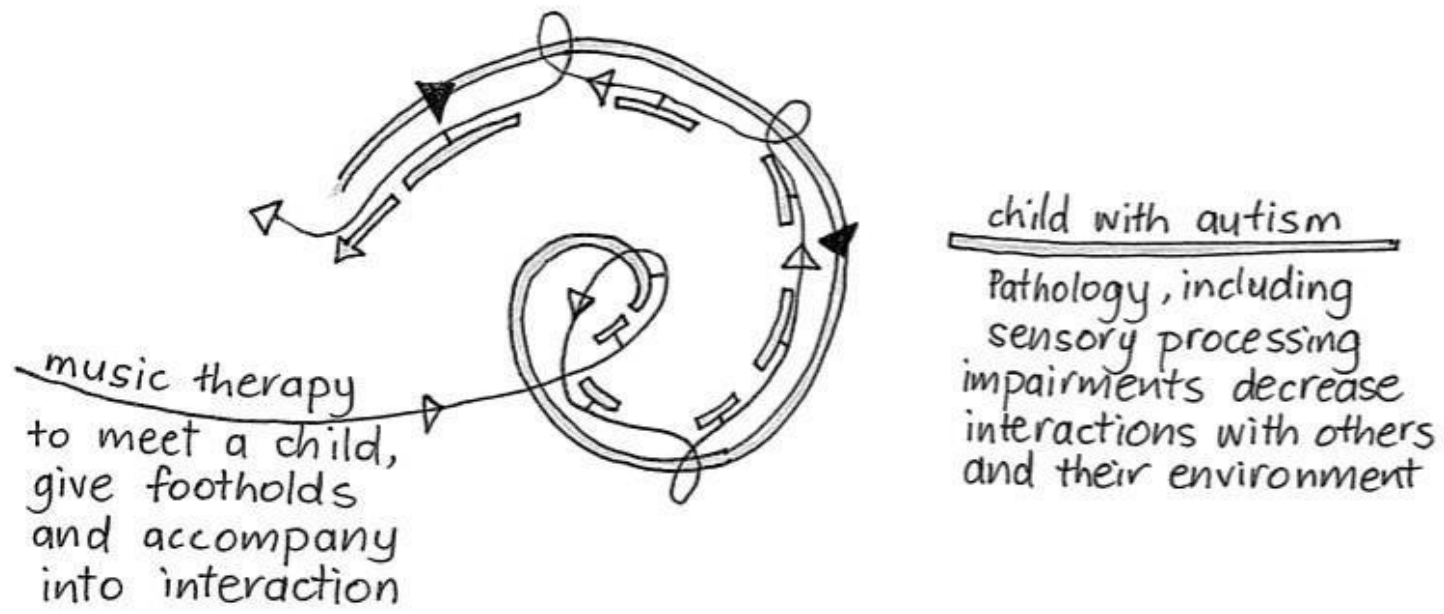

Diagram of Themes identified in the Findings during data analysis:

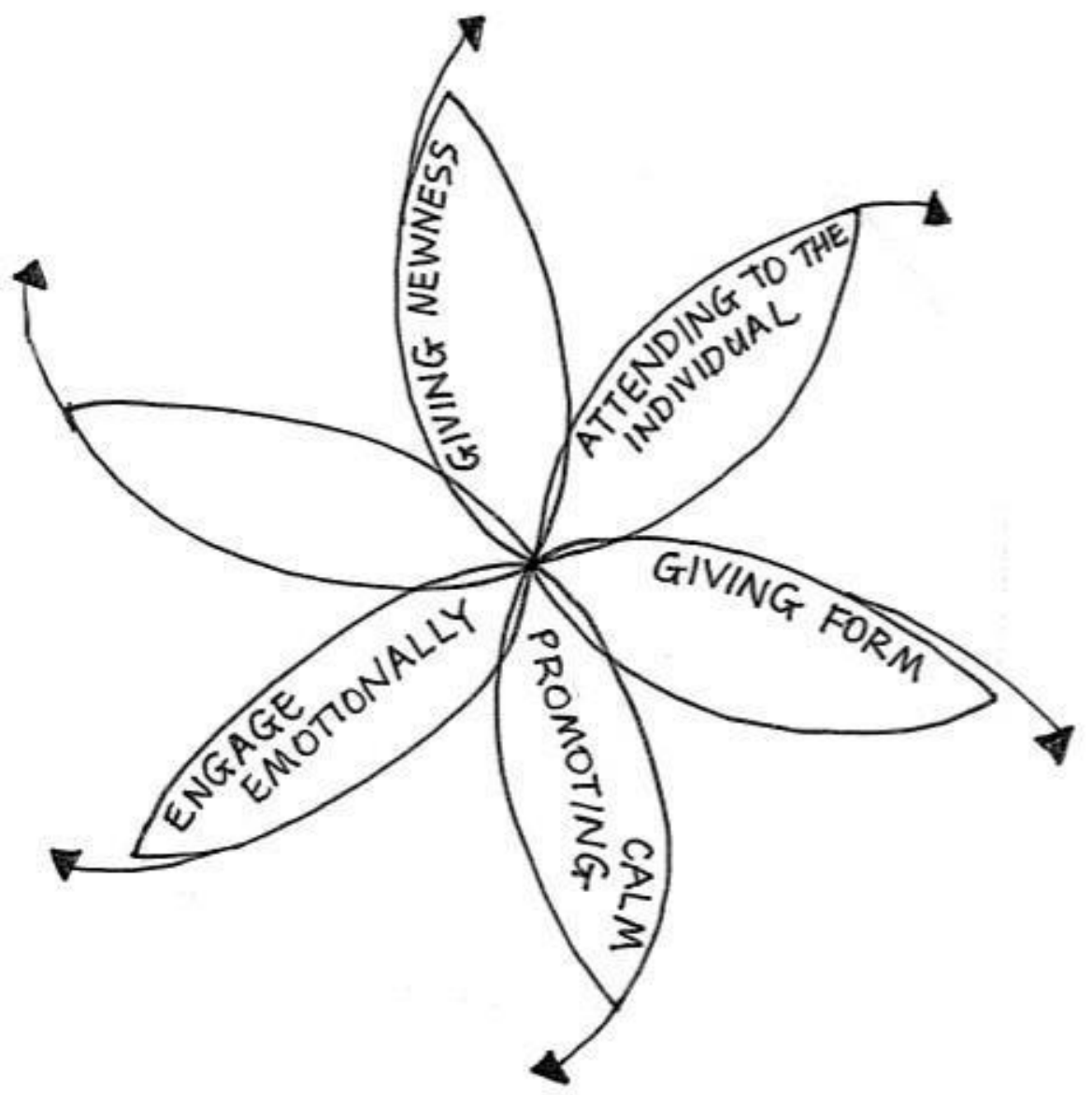

One section is empty so it tips forward to keep momentum. The arrows indicate this movement and, like a crochet hook, weave in responses from individuals and the group. 
CHANGES IN WHAT I SEARCHED FOR AND READ were an indication of a shift in thinking and at these times my supervisor remarked on my increased enthusiasm and engagement with the clinical work. Initially, I read about autism and music therapy, group music therapy, with a cursory glance at community music therapy. I had an assumption that group experiences of belonging would support interactions. I read about play and the impact of autism on play, therefore, also on learning and development. Here, my attitude in group music was influenced by ideas about music play to entice and connect emotionally with the children, as well as giving play opportunities as footholds to draw a child out of individual play and into interactions. Noticing that being playful wasn't enough, I sought out readings on sensory processing, as a way to understand an individual's obstacles to interaction. At the time of writing up I was interested to explore literature about foundational human connections of infant's early communication as supporting of children's interactions.

\section{JOURNEY OF REFLEXIVITY:}

I feel I have begun the journey of becoming a reflexive therapist. Seeking to work within the social context of clients, (i.e. the school) identifying needs and how music therapy might support the client in their social context, allowing the client and their context to inform and question my approach, adapting goals and practice through new knowledge from clinical experiences, interdisciplinary insights and ongoing reading, and staying with the messy bits. This was a recursive process.

Although I could only find what I was able to see, and to learn what was meaningful for me, I was deeply influenced by the children and the work; the research process gave me license to be in the learning. In the secondary analysis of data of my clinical notes I identified hard work, attending to the individual, promoting calm, importance of newness and giving form for my student music therapy practice. These themes had immediate relevance to me. This is what I mean by reflexive: an awareness of my own interpretation and the impact of this; an ongoing recursive process of learning through the interdependent facets of clinical work: practice, reflection and theory (written or oral) It is in constant movement.

The more I allowed my findings to have a place within, the more it opened my capacity to "interact" with the work. For example, the Findings were a mirror which reflected back to me, indications growth as a student - to engage with the hard work, to attend to my own needs and my obstacles to interacting; Calm related to my being "in the zone" for optimal therapeutic availability, appreciating the importance of newness and exploring, wondering and experimenting rather than my inclination to "make do". And finally, my hardest lesson: Giving Form.

This related to my preference to work with what others give, more than giving something myself. While this preference has strengths, e.g. can facilitate communication and a trusting relationship, I think I needed to balance my approach with giving meat to chew on and work to do. To per-form means to 
bring out the self: I needed to "bring out" the children into interaction, and in the process I grew in the capacity to be more of who I am. Journal entry: "that's how I am" capacity, as I expand my own, I increase my capacity to do facilitate others. My end of year assessment noted my increased confidence and competence - there was a mutual flow between influencing and being influenced by the clinical work; which is what I understand as reflexivity.

Postscript: At the time of final write-up and printing, I felt overwhelmed by the organisational task. Perhaps this has relevance to understanding the impact of severe sensory processing difficulties; music therapy with children with autism is maybe most helpful when it helps to organise their experiences, be grounding and connecting.

\section{EXAMPLE OF REFLECTION:}

What I did to in group music therapy seemed to be more helpful for some children than others. For example, in the afternoon group, I expected more interaction and responses from two children I shall call $A$ and $B$, considered to have more cognitive abilities. However, it was two other children (considered to have less cognitive abilities) who particularly showed more times of prolonged interaction with me and in music. The two children A and B, sometimes hovered near me, and at the time I did not know how to support the possibility for them to join in. Recognising my assumption that all children wanted to interact and be part of music play, and my focus on sensory processing difficulties, I wondered about what else I needed to attune to these two children.

\section{PERSONAL RELEVANCE: HARD WORK}

There was a process over the ten months through this theme of Hard Work, where initially I identified it in the children. I read about the importance of play as a means and context for child development. I was quite alarmed to consider the implications that sensory processing difficulties, common in autism, have on play, thus learning and development. It motivated me to try to find ways to develop play interactions. In August I became aware of overcoming my own obstacles. This was through the experience of family crisis and needing to take time off studies. I made a link between my obstacles and what I was expecting of the children. This experience, of attending to my own needs, was liberating: I learned I was more able to attend to the needs of other. This had implications for attending to sensory and emotional needs of the children and their availability for interaction. Accepting my experiences of 'limit' increased my capacity to be more who I am, and this expanded my capacity to engage in the work. Further connection of my experience with the children's experience happened when I read a phrase about music therapy connecting inner worlds of therapist and client. It somehow gave me the license to do what I do well. The concept of empathy felt like an energy which made possible both connection and a way through the hard work. Life is strange....I wrote in my research journal, and it seemed suddenly the work wasn't so hard. 
Alvesson, M., \& Sköldberg, K. (2009). Reflexive methodology: New vistas for qualitative research London : SAGE, 2009.

Ansdell, G., \& Pavlicevic, M. (2001). Beginning Research in the Arts Therapies : A Practical Guide. London: Jessica Kingsley Publishers.

Ansdell, G., \& Pavlicevic, M. (2010). Practicing 'Gentle Empiricism'-The Nordoff Robbins Research Heritage. Music Therapy Perspectives, 28(2), 131-139.

Ayers, J. (1979). Sensory integration and the child. Los Angeles: Western Psychological Services.

Barnes, G. (2010). Moments of Meeting: Difficulties and developments in shared attention, interaction, and communication with children with autism during two years of music therapy in a public preschool class. Proquest LLC.

Barton, E., \& Pavilanis, R. (2012). Teaching Pretend Play to Young Children with Autism. Young Exceptional Children, 15(1).

Berger, D. (2009). On developing music therapy goals and objectives. Voices: A World Forum For Music Therapy, 9(1).

Berger, D. S. (2002). Music therapy, sensory integration and the autistic child London : Jessica Kingsley, 2002.

Bevan-Brown, J., Carroll-Lind, J., Kearney, A., Sperl, B., \& Sutherland, M. (2008). Making Assumptions vs. Building Relationships: Lessons from a Participatory Action Research Project to Identify Effective Practices for Learners with Autism Spectrum Disorder. Kairaranga, 9.

Braun, V., \& Clarke, V. (2006). Using thematic analysis in psychology. Qualitative Research in Psychology, 3(2). doi: 10.1191/1478088706qp063oa

Corke, M. (2011). Using Playful Practice to Communicate with Special Children: New York: Routledge, Taylor \& Francis Group.

Dmitriadis, T., \& Smeijsters, H. (2011). Autistic spectrum disorder and music therapy: Theory underpinning practice. Nordic Journal of Music Therapy, 20(2).

Drake, T. (2008). Back to basics: Community-based music therapy for vulnerable young children and their parents. In A. Oldfield \& C.Flower (Eds.), Music Therapy with children and their families: London; Philadelphia: J. Kingsley Publishers, 2008.

Ely, M., Vinz, R., Downing, M., \& Anzul, M. (1997). On writing qualitative research : Living by words London; Washington, D.C. : Falmer Press, 1997.

Firmin, M. (2008). Themes In L. Given (Ed.), The SAGE Encyclopedia of Qualitative Research Methods. Thousand Oaks, CA: SAGE Publications, Inc. doi: 10.4135/9781412963909

Gal, E., Dyck, M., \& Passmore, A. (2002). Sensory Differences and Stereotyped Movements in Children with Autism. Behaviour Change, 19(4).

Garred, R. (2006). Music as therapy: a dialogical perspective Gilsum, NH : Barcelona Publishers.

Gattino, G., Riesgo, R., Longo, D., Leite, J., \& Faccini, L. (2011). Effects of relational music therapy on communication of children with autism; a randomised control study. Nordic Journal of Music Therapy, 20(2). doi: 10.1080/08098131.2011.566933

Gold, C., Wigram, T., \& Elefant, C. (2010). Music therapy for autistic spectrum disorder Cochrane Database of Systematic Reviews 2006, (1). Retrieved from doi:10.1002/14651858.CD004381.pub2.

Goodman, K. (2007). Music therapy groupwork with special needs children: The evolving process: Springfield, Ill.: Charles C Thomas.

Green, D. (2008). Categories. . In L. Given (Ed.), The SAGE Encyclopedia of Qualitative Research Methods. Thousand Oaks, CA: SAGE Publications, Inc. doi: $10.4135 / 9781412963909$ 
Grogan, K., \& Knak, D. (2002). A children's group: An exploration of the framework necessary for therapeutic work. In A. Davies \& E. Richards (Eds.), Music therapy and group work Sound company. London and Philadelphia: Jessica Kingsley Pub.

Heaton, J. (2004). Reworking qualitative data London: SAGE

Hennink, M., Hutter, I., \& Bailey, A. (2011). Qualitative Research Methods. London: Sage Publications.

Holck, U. (2004). Interaction themes in music therapy: Definition and delimitation. Nordic Journal of Music Therapy, 13(1), 3. Retrieved from http://www.tandfonline.com

Hornbach, C. (2011). Building community to elicit responses in early childhood music classes. In S. L. Burton \& C. C. Taggart (Eds.), Collected Work: Learning from young children: Research in early childhood music. (pp. 63-78). Lanham, MD. : Rowman \& Littlefield Education.

Ingersoll, B., \& Schreibman, L. (2006). Teaching Reciprocal Imitation Skills to Young Children with Autism Using a Naturalistic Behavioral Approach: Effects on Language, Pretend Play, and Joint Attention. Journal of Autism \& Developmental Disorders, 36(4). doi: 10.1007/s10803-006-0089-y

Johnson, W., \& Robinson, L. (2011). Towards standardisation of the Sensory Profile Checklist Revisited: Perceptual and Sensory Sensitivities in Autism Spectrum Conditions. The University of Edinburgh Retrieved from http://hdl.handle.net/1842/5308

Kim, J., Wigram, T., \& Gold, C. (2009). Emotional, motivational and interpersonal responsiveness of children with autism in improvisational music therapy. Autism, 13(4), 389 - 409. Retrieved from

Lane, A., Young, R., Baker, A., \& Angley, M. (2010). Sensory processing subtypes in autism: Association with adaptive behavior. [Article]. Journal of Autism \& Developmental Disorders, 40(1). doi: 10.1007/s10803-009-0840-2

Leekham, S., Prior, M., \& Uljarevic, M. (2011). Restricted and repetitive behaviours in autism spectrum disorders: A review of literature in the last decade. Psychological Bulletin, $137(4)$.

Loth, H. (2008). Music therapy groups for families with a learning disabled toddler Bridging some gaps. In A. Oldfield \& C. Flower (Eds.), Music therapy with children and their families. London: J. Kingsley

Mastrangelo, S. (2009). Play and the child with autism spectrum disorder: From possibilities to practice. International Journal of Play Therapy, 18(1). doi: 10.1037/a0013810

Matson, J., Beighley, J., \& Turygin, N. (2012). Autism Diagnosis and Screening: Factors to Consider in Differential Diagnosis. Research in Autism Spectrum Disorders, 6(1).

McMenamin, T. (2011). The tenacity of special schools in an inclusive policy environment: the New Zealand situation 1996-2010. [Article]. Support for Learning, 26(3), 97-102. doi: 10.1111/j.1467-9604.2011.01486.x

Miller, R. (2011). Vygotsky in Perspective Retrieved from http://MASSEY.eblib.com.au/patron/FullRecord.aspx?p=691936

Ministry of Education, N. Z. (2012). Special Education: Success for All. Wellington, New Zealand: Author. Retrieved from http://www.minedu.govt.nz/NZEducation/EducationPolicies/SpecialEducation/OurWor kProgramme/SuccessForAll.aspx.

Nienhuis, K. (2005). The institutional family : Group music therapy in an institutional setting. University of Pretoria Retrieved from http://upetd.up.ac.za/thesis/available/etd02232005-114517/

Nordoff, P., Robbins, C., \& Marcus, D. (2007). Creative music therapy : a guide to fostering clinical musicianship (2 ed.): Gilsum, N.H. : Barcelona Pub.

O'Connor, R. (2005). Creating connections: an insight into the development of relationships within a short-term, psychodynamic music therapy group In C. Flower (Ed.), No man is an island: Groups, partnerships and teams in music therapy London : British Society for Music Therapy. 
Pavlicevic, M. (2012). Between beats: Group music therapy transforming people and places. In R. MacDonald, G. Kreutz \& L. Mitchell (Eds.), Collected Work: Music, Health and Wellbeing Oxford University Press.

Rickson, D. (2010). The development of a music therapy school consultation protocol for students with high or very high special education needs. Wellington, New Zealand. Retrieved from http://ezproxy.massey.ac.nz/login?url=http://search.ebscohost.com/login.aspx?direct=tr ue $\& \mathrm{db}=$ cat00245a \&AN=massey.b2357958\&site=eds-live http://hdl.handle.net/10179/1881

Shoemark, H. (2009). Music therapy: An exercise in humanity. Australian Journal of Music Therapy, 20(Special issue).

Simpson, K., \& Keen, D. (2011). Music Interventions for Children with Autism: Narrative Review of the Literature. Journal of Autism and Developmental Disorders, 41(11).

Stewart, R. (2002). Combined efforts: Increasing social-emotional communication with children with autistic spectrum disorder using psychodynamic music therapy and Division TEACCH communication programme. In A. Davies \& E. Richards (Eds.), Collected Work: Music therapy and group work: Sound company. London; Philadelphia: J. Kingsley.

Stige, B., \& Aaro, L. (2012). Invitation to community music therapy New York: Routledge. Stige, B., Ansdell, G., Elefant, C., \& Pavlicevic, M. (2010). Where music helps: Community music therapy in action and reflection. Farnham, England; Burlington, VT: Ashgate.

Talay-Ongan, A., \& Wood, K. (2000). Unusual Sensory Sensitivities in Autism: A possible crossroads. International Journal of Disability, Development and Education, 47(2), 201-212. doi: http://dx.doi.org/10.1080/713671112

Tomchek, S., \& Dunn, W. (2007). Sensory Processing in Children With and Without Autism: A Comparative Study Using the Short Sensory Profile. American Journal of Occupational Therapy 61, 190-200. doi: doi:10.5014/ajot.61.2.190

Twyford, K. (2009). Finding a Niche: Establishing a Role for Music Therapy Within the Ministry of Education, Special Education NZ. [Article]. New Zealand Journal of Music Therapy(7), 6-31.

Tyler, H. (2002). Working, playing and relating: Issues in group music therapy for children with special needs. In A. Davies \& E. Richards (Eds.), Collected Work: Music therapy and group work: Sound company. London; Philadelphia: J. Kingsley.

Whitman, T., \& DeWitt, N. (2011). Key Learning Skills for Children with Autism Spectrum Disorders : A Blueprint for Life. London; Philadelphia: J. Kingsley.

Wieder, S., \& Greenspan, S. I. (2003). Climbing the symbolic ladder in the DIR model through floor time/interactive play. Autism: The International Journal of Research \& Practice, $7(4)$.

Wigram, T. (2004). Improvisation: Methods and techniques for music therapy clinicians, educators and students. London: J. Kingsley.

Zeedyk, M. (2008). Promoting social interaction for individuals with communicative impairments : making contact London; Philadelphia: J.Kingsley. 